\title{
Design and Synthesis of Chiral Spiro Ligands
}

\author{
Gan B. Bajracharya* \\ Nepal Academy of Science and Technology (NAST), Khumaltar, Lalitpur, Nepal \\ E-mail: ganbajracharya@yahoo.com
}

\begin{abstract}
Tremendous progress has been made in design and synthesis of chiral spiro ligands and researches in finding their utility have led development of several asymmetric- and organo-catalysis. This review describes recent advances in synthesis of chiral spiro ligands.
\end{abstract}

Keywords: asymmetric synthesis, metal catalysis, spiro ligands

\section{Introduction}

The adjective chiral is derived from the Greek cheir meaning "hand". A hand has no symmetry plane since the right half of a hand is not a mirror image of the left half. Left and right hands are chiral that do not superimpose on each other and are not identical. The phenomenon of handedness or chirality exhibits in many molecules of the Nature and are importantly biologically active. Unfortunately, Nature supplies such bioactive compounds in limited quantities and usually only single isomers are available after tedious isolation processes. Thus the scientific community has focused on asymmetric synthesis of organic compounds through the induction of chirality by employing chiral reagents, where synthesis of all the enantiomers is feasible. ${ }^{1}$ In particular, the metal-catalyzed asymmetric synthesis has emerged as a powerful and economic tool for the synthesis of optically active organic compounds of biological importance, in which, the use of a suitable chiral ligand can provide an effective asymmetric environment for chirality induction. The design and synthesis of an efficient chiral ligand, with strong metal affinity and a suitable chiral backbone, is one of the most challenging tasks and plays a central role for the success. Additional benefits are gained when the chiral ligands could easily be modified to achieve high turn over number in the catalytic reactions.

In 1980s, Noyori reported an outstanding diphosphine ligand 2,2'-bis(diphenylphosphino)-1,1'binaphthyl (BINAP) with a biaryl scaffold, which is one of the most commonly used chiral ligands in the transition metal-catalyzed asymmetric reactions. ${ }^{2}$ The configurational stability of this type of ligand depends on the restriction in rotation around the bridged-bond due to the bulk of the ortho-substituents and thus exhibits an axial chirality. Searching of new chiral ligands over the past decades has led to synthesis of several bidentate phosphines, diamines, oxazolines and hybrid $P, N$ ligands (Figure 1). ${ }^{3}$ In contrast, spirane with two rings and one common spiro atom (generally carbon) is rigid. This rigid spirocyclic framework minimizes the number of possible conformations and consequently benefits in selectivity. The parent spiro[4,4]nonane itself is achiral, however, the spirane chirality is observed when suitable substituents are introduced in the perpendicular rings that gives rise $C_{2}$-symmetric structural feature (Figure 2). The introduction of substituents in spirane ring for creation of chiral skeleton results in more than one chiral center in the molecule and thereby increases the difficulties in its synthesis and resolution.

\section{* Corresponding author}


The synthesis of a spiro skeleton can be traced back to the late $1890 \mathrm{~s}^{4}$ von Baeyer has coined the term "spirocyclane" for the pretzel like bicyclic hydrocarbons in $1900 .^{5}$ After one century of its discovery, spiro skeleton has gained interests of scientific community to be used as chiral auxiliaries. The purpose of this review is to summarize the design and synthesis of chiral spiro ligands, which have already been used in metal catalysis. ${ }^{6}$

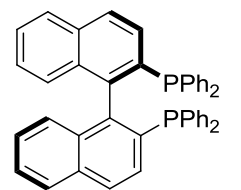

$(R)$-BINAP

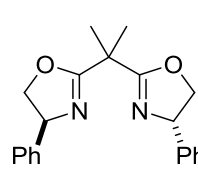

$(\mathrm{S}, \mathrm{S})-\mathrm{Ph}-\mathrm{BOX}$

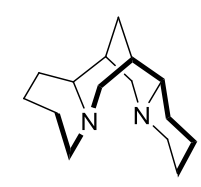

(-)-spartein

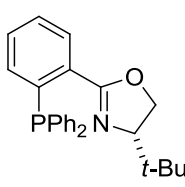

(S)-t-Bu-PHOX

Figure 1: Representative examples of chiral ligands.

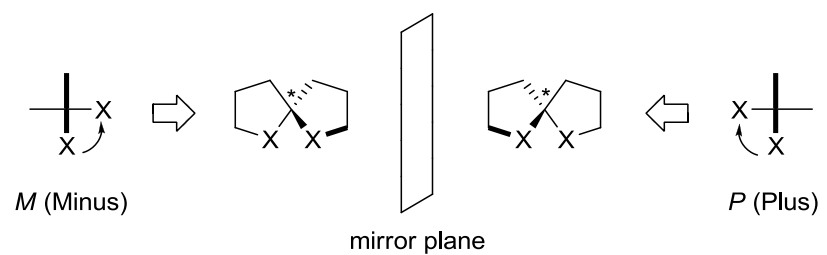

Figure 2: Spirane chirality.

\section{[m,n]Alkane-based Spiro Ligands}

\section{Spiro[4.4]nonane-1,6-diol (Spirol)}

Spiro[4.4]nonane-1,6-diol (Spirol) can exist in three diastereomeric forms: cis,cis 1, cis,trans 2 and trans,trans 3 (Figure 3). Cram, Gerlach, Harada and their coworkers have independently reported the synthesis of Spirol. ${ }^{7}$ In 1993, an improved synthesis of cis, cis-1 was reported by Keay et al. (Scheme 1). ${ }^{8}$ Alkylation of the anion of ethyl 2-oxocyclopentanecarboxylate (4) with ethyl 4-bromobutyrate produced the diester, which subsequently hydrolyzed and decarboxylated by refluxing in $10 \% \mathrm{HCl}$ to give 5. The spiro cyclization of $\mathbf{5}$ was affected by treating with $p$-toluenesulphonic acid in refluxing toluene (through azeotropic removal of the water) producing racemic dione $\mathbf{6}$. Treatment of $\mathbf{6}$ with lithium tert-butyldiisobutylaluminium hydride selectively produced racemic cis,cis-1 with $51 \%$ yield in four steps. The choice of reducing agent in this step was found crucial for the diastereoselectivity. Chan et al. have reported predominantly formation of cis,trans-2 by catalytic hydrogenation of dione $\mathbf{6}$ in the presence of

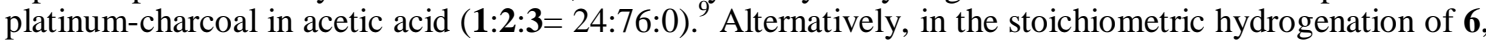
the use of borane in THF was effective $(\mathbf{1}: \mathbf{2 : 3}=16: 82: 2)$. On the other hand, the chiral oxazaborolidine reagent-catalyzed reduction of dione $\mathbf{6}$ produced trans, trans $\mathbf{3}$ stereoselectively. Spirol can be resolved by column chromatographic separation of the diastereomers that obtained by treating with either $(+)$ camphor and $p$-toluenesulphonic acid $^{8}$ or $d$-camphorsulphonyl chloride in pyridine, ${ }^{9}$ followed by hydrolysis. Spirols are not explored their selves as chiral ligands in the metal catalysis but are further converted in to the phosphine and nitrogen based ligands and then utilized in metal catalysis.

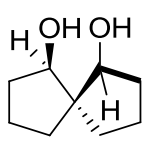

cis, cis-1

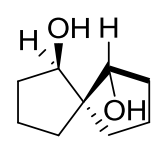

cis,trans-2

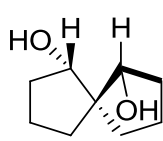

trans,trans-3

Figure 3: Three diastereomers of Spirol. 
Review

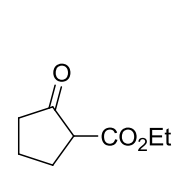

4

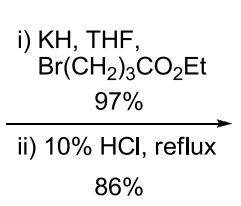

$86 \%$

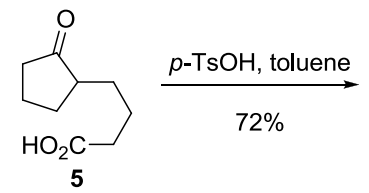

Scheme 1: Synthesis of cis,cis-Spirol.

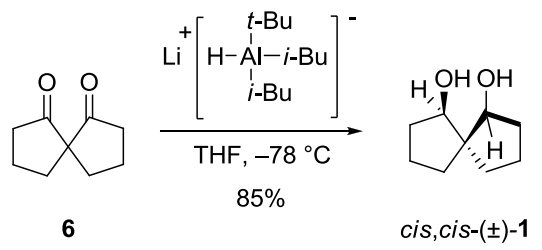

\section{Spiro bisphosphinite (SpirOP)}

In the pioneering report, Chan and Jiang et al. described synthesis of chiral 1,6-spiro bisphosphinite ligand (SpirOP) 7 through the reaction of chlorodiphenylphosphine with optically pure cis,cis$(1 R, 5 R, 6 R)$-Spirol 1 in the presence of $N, N$-dimethyl-4-diaminopyridine (DMAP) (Scheme 2). ${ }^{10}$ SpirOP 7 was utilized in the Rh-catalyzed asymmetric hydrogenation reactions. ${ }^{11}$

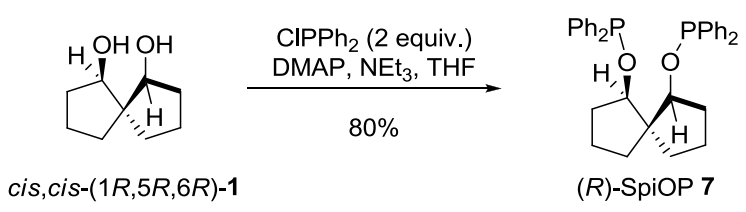

Scheme 2: Synthesis of SpirOP.

\section{Spiro diphosphite}

Jiang, Xue and their coworkers have prepared chiral spiro diphosphite ligands 9 by the reaction of cis,trans-(1R,5R,6S)-Spirol 2 with chlorophosphites 8 (Scheme 3). ${ }^{12}$ Related diphosphites are not produced from cis,cis- $(1 R, 5 R, 6 R)$-Spirol 1 due to the steric constraints. In the presence of ligands $\mathbf{9}$ and syn gas $\left(\mathrm{CO}: \mathrm{H}_{2}=1: 1\right)$, the Rh-catalyzed asymmetric hydroformylation of styrenes is reported.

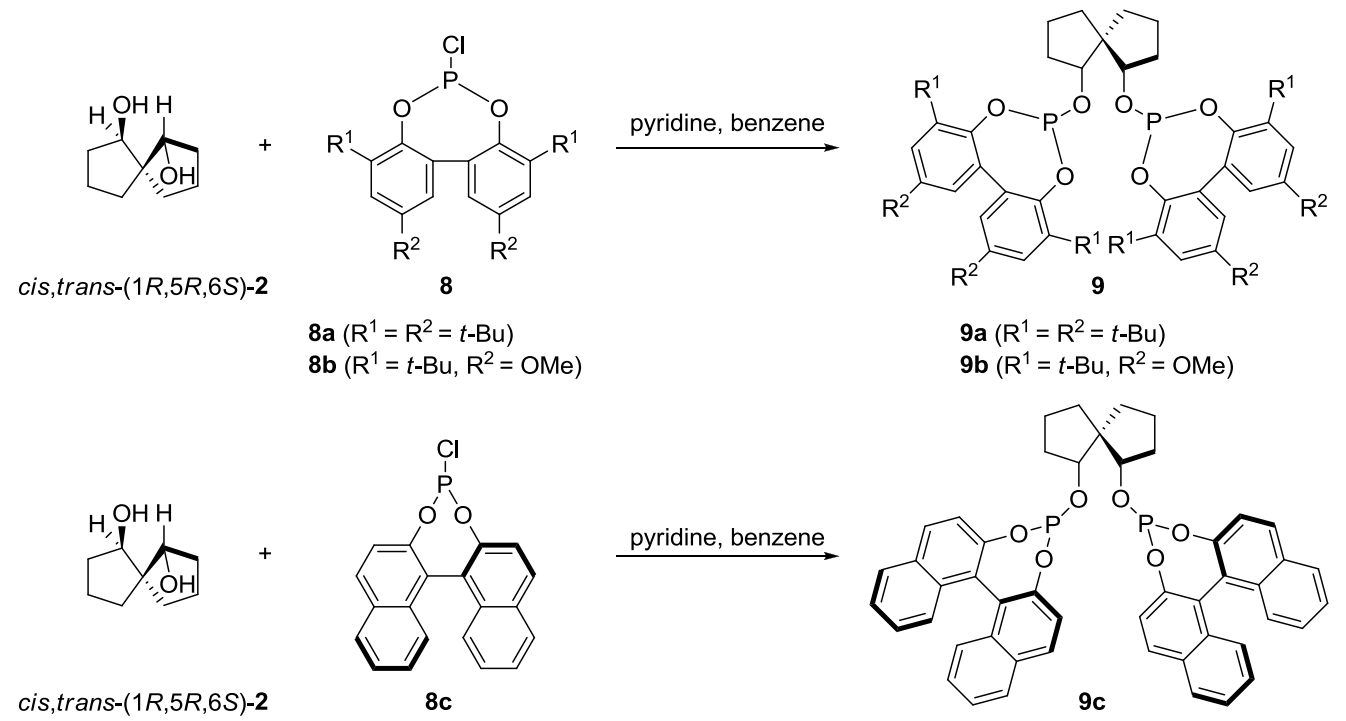

Scheme 3: Synthesis of spiro diphosphites. 


\section{Spiro bisphosphinamidite (SpiroNP)}

Chan et al. have reported chiral spiro bisphosphinamidite ligand (SpiroNP) 13 (Scheme 4). ${ }^{13}$ Dimesylate $(1 S, 5 R, 6 S)-\mathbf{1 0}$, obtained from trans,trans-(1S,5R,6S)-3, upon treatment with sodium azide produced diazide $(1 R, 5 R, 6 R)-\mathbf{1 1}$. The $\mathrm{Pd} / \mathrm{C}$ reduction of diazide 11 with molecular hydrogen produced

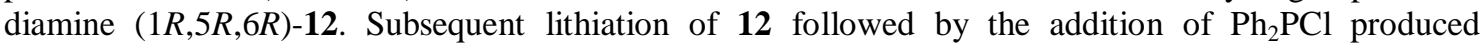
$(1 R, 5 R, 6 R)-13$. The application of SpiroNP has been shown in the cationic Rh-catalyzed asymmetric hydrogenation reaction.

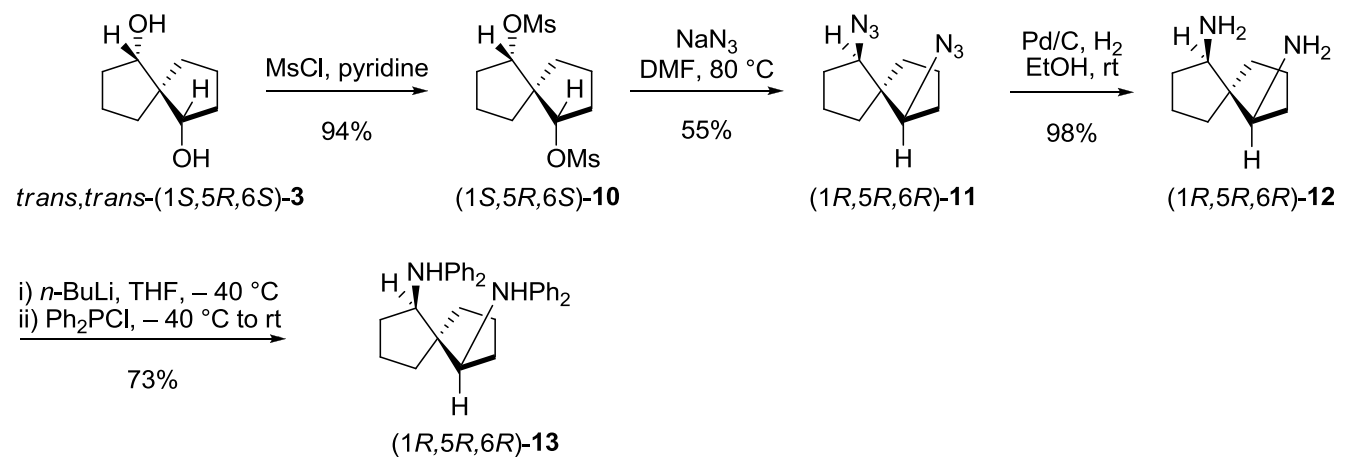

Scheme 4: Synthesis of SpiroNP.

\section{Spiro phosphino-oxazoline}

Keay et al. have synthesized spiro phosphino-oxazoline 22 (Scheme 5). ${ }^{14}$ Addition of lactone $\mathbf{1 4}$ to the Grignard reagent produced a diol, which was dehydrated under acidic conditions yielding 16. DessMartin oxidation of $\mathbf{1 6}$ followed by oxime formation produced 17. Oxime $\mathbf{1 7}$ was stirred with $\mathrm{NaClO}$ to produce a nitrile oxide, which underwent intramolecular 1,3-dipolar cycloaddition giving 18. $\mathrm{LiAlH}_{4}$ reduction of 18 produced spiro amino alcohol $( \pm)$-19. Resolution of $( \pm)-\mathbf{1 9}$ with (-)-mandelic acid gave $(+)-19 .{ }^{14 \mathrm{~b}}$ Coupling of (+)-19 and $\mathbf{2 0}$ by refluxing with $\mathrm{ZnCl}_{2}$ produced (+)-21, which on treating with 2,2'-dipyridyl gave (+)-22. The application of spiro phosphino-oxazoline was shown in the Pd-catalyzed alkylation reaction. ${ }^{14 a}$

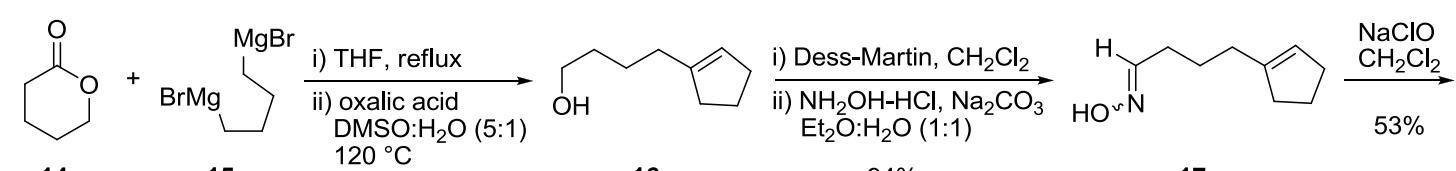

14

15

$71 \%$

16

$94 \%$

17

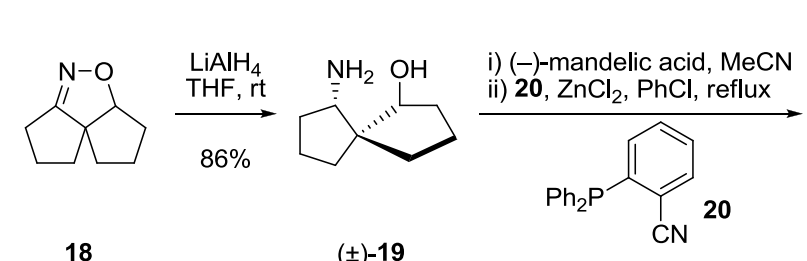

18

(士)-19

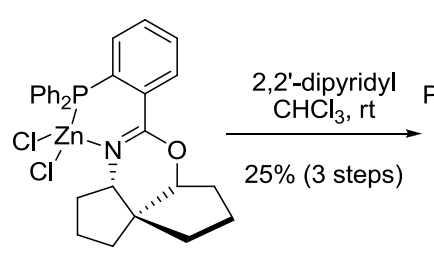

(+)-21

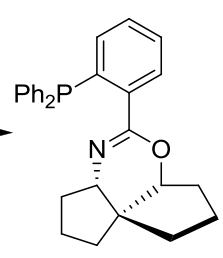

(+)-22

Scheme 5: Synthesis of spiro phosphino-oxazoline. 


\section{Spiro bis(isoxazoline) (SPRIX)}

In 1999, Sasai et al. reported novel chiral spiro bis(isoxazoline) ligands (SPRIXs) 28-30 bearing two isoxazoline rings to coordinate with a metal center. ${ }^{15}$ SPRIXs 28-30 were synthesized starting from diethyl malonate (23) via intramolecular double nitrile oxide cycloaddition as a key step, which constructs four rings and a spiro backbone in one step (Scheme 6). Compound $\mathbf{2 3}$ was treated with alkenyl bromide $\mathbf{2 4}$ in the presence of a base to produce malonate $\mathbf{2 5}$, which was subsequently reduced with $\mathrm{LiAlH}_{4}$ producing diol 26. After Swern oxidation of 26, the resulting dialdehyde was treated with $\mathrm{NH}_{2} \mathrm{OH}-\mathrm{HCl}$ in pyridine to produce dioxime $\mathbf{2 7}$ as a single isomer. All the possible diastereomers were obtained using intramolecular double nitrile oxide cycloaddition of $\mathbf{2 7}$ and each diastereomer was easily separated using silica gel column chromatography. $(M, S, S)$-H-[5.5]-SPRIX 28e was not obtained because of a steric repulsion between the two nitrogens of isoxazoline rings.

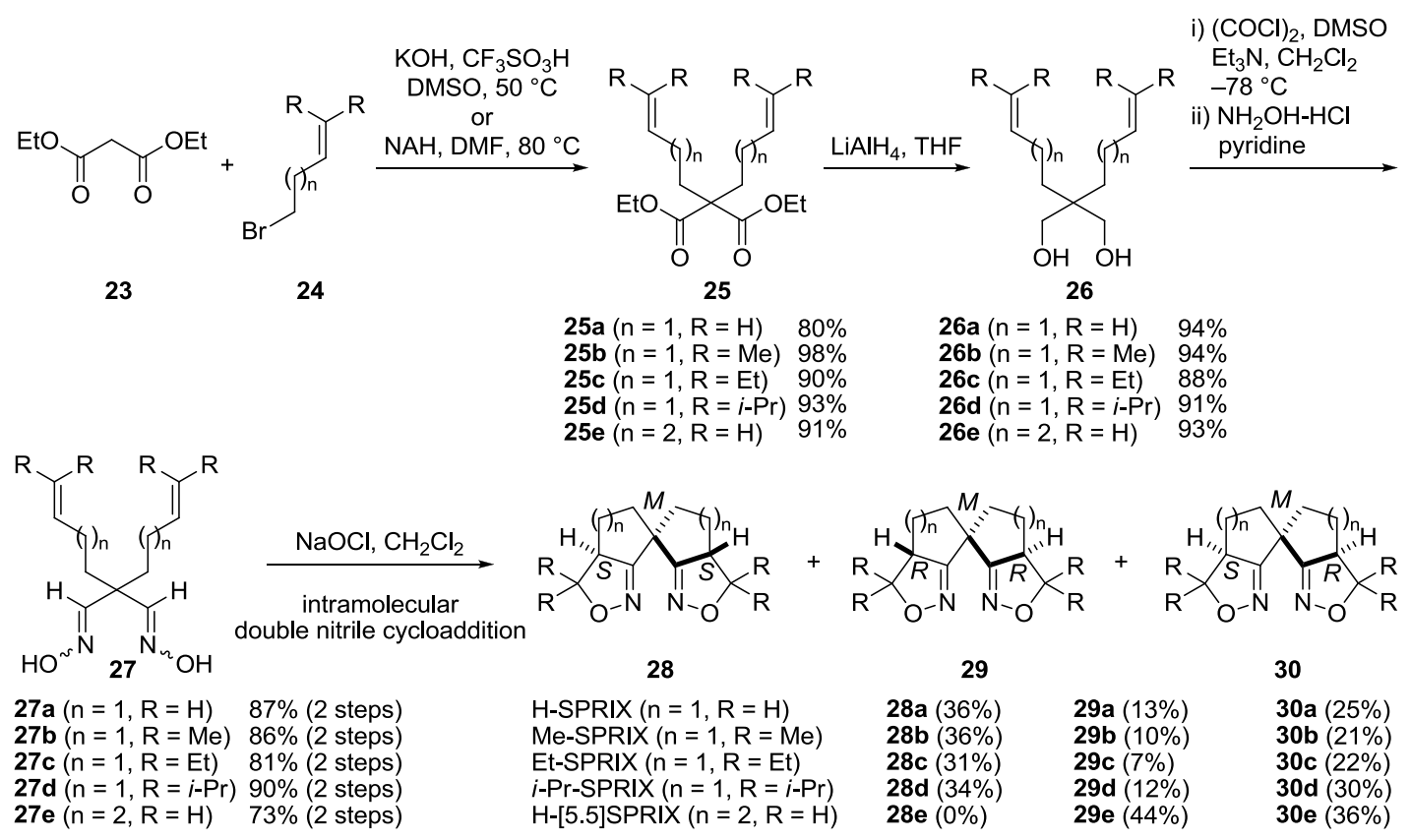

Scheme 6: Synthesis of SPRIXs.

Enantiomerically pure SPRIXs were obtained by chiral stationary phase column chromatography [Daicel Chiralpak AD $(\varnothing 2 \mathrm{~cm} \times 25 \mathrm{~cm})$ ]. Later, tetraisopropyl-substituted spiro bis(isoxazoline) $\quad(i$-PrSPRIX, 28d) was successfully resolved by using ortho-palladated benzylamine derivative as a resolving agent via the separation of a mixture of the diastereomeric palladium complexes of $( \pm)$-28d (Scheme 7). ${ }^{16}$ The treatment of $( \pm)$-28d with 0.5 equivalents of di- $\mu$-chlorobis $\{(R)-2$-[1-(dimethylamino)ethyl]phenyl$C, N$ \}dipalladium (II) $(R, R)$-31 followed by addition of 4 equivalents of aqueous $\mathrm{NH}_{4} \mathrm{PF}_{6}$ in $\mathrm{MeOH}$ produced 1:1 diasteromeric mixture of cationic palladium complexes $(R, P, R, R)-\mathbf{3 2}$ and $(R, M, S, S)-\mathbf{3 3}$. After fractional recrystallization from dichloromethane/diethyl ether solution, the pure sample of $(R, P, R, R)-32$ was obtained as a colorless crystal. Optically pure $(P, R, R)$ enantiomer of $i$-Pr-SPRIX $28 d$ was obtained by decomplexation from $(R, P, R, R)$-32 through the ligand exchange reaction using 1,2bis(diphenylphosphino)ethane (dppe).

Using SPRIXs, Pd-catalyzed Wacker-type cyclization of alkenyl alcohols and tandem cyclization of dialkenyl alcohols (see: Scheme 12), ${ }^{17}$ intramolecular aminocarbonylation of alkenyl amines and 
amides, ${ }^{18}$ cyclization of (Z)-4'-acetoxy-2'-butenyl-2-alkynoates, ${ }^{19}$ 5-endo-trig-type cyclization of $\beta, \gamma$ unsaturated carbonyl compounds ${ }^{20}$ were developed. Furthermore, an interesting application of SPRIX has been found in the dicationic palladium-catalyzed enantioselective isotactic copolymerization of $\mathrm{CO}$ with styrenes. ${ }^{21}$ Recently, the first asymmetric $\mathrm{Pd}^{\mathrm{II}} / \mathrm{Pd}^{\mathrm{IV}}$ catalysis was achieved by using a combination of a hypervalent iodine reagent and SPRIX to synthesize bicylo[3.1.0] hexanes via oxidative cycliation of enynes. $^{22}$

Next, using an optically pure olefin derivative $\mathbf{3 4}$, new chiral spiro bis(isoxazoline) ligands $\mathbf{3 7}$ and $\mathbf{3 8}$ were synthesized following the general route (Scheme 8). ${ }^{23}$ Only two diastereomers $\mathbf{3 7}$ and $\mathbf{3 8}$ were obtained with a ratio of 12:88 in overall $51 \%$ yield. Importantly, these ligands were obtained in an optically pure form by simple column chromatography. MM2 calculation revealed that $\mathbf{3 7}$ have comparably a short $N-N$ atomic distance $(3.04 \AA$ vs. $4.09 \AA$ of 38) and a small out-of-plane angle between the two $\mathrm{C}=\mathrm{N}$ bonds $\left(59.8^{\circ}\right.$ vs. $89.5^{\circ}$ of 38) indicating it's potential for a metal coordination. Using ligand 37, the first example of the bis(isoxazoline) ligand-promoted, $\mathrm{Cu}$-catalyzed gloxylate-ene reaction of olefins to produce alkenoates was reported.

(士)-28d
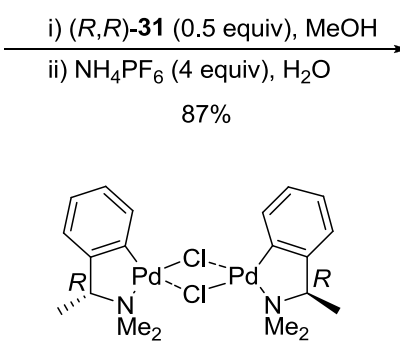

31

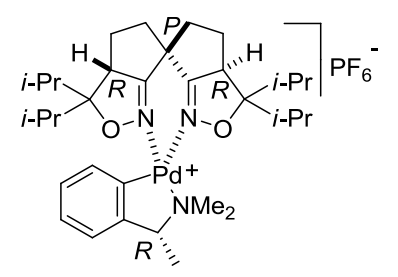

$(R, P, R, R)-32$

recrystallization
$37 \%$

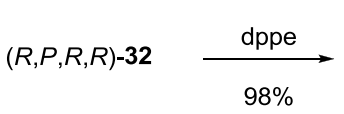

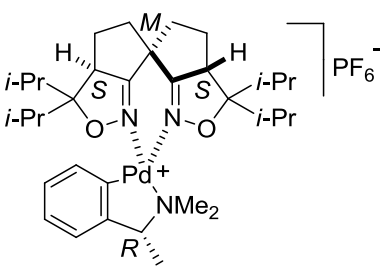

$(R, M, S, S)-33$

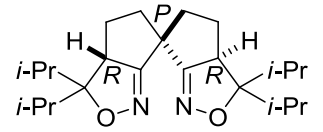

$(P, R, R)-\mathbf{2 8 d}$

Scheme 7: Resolution of i-Pr-SPRIX.
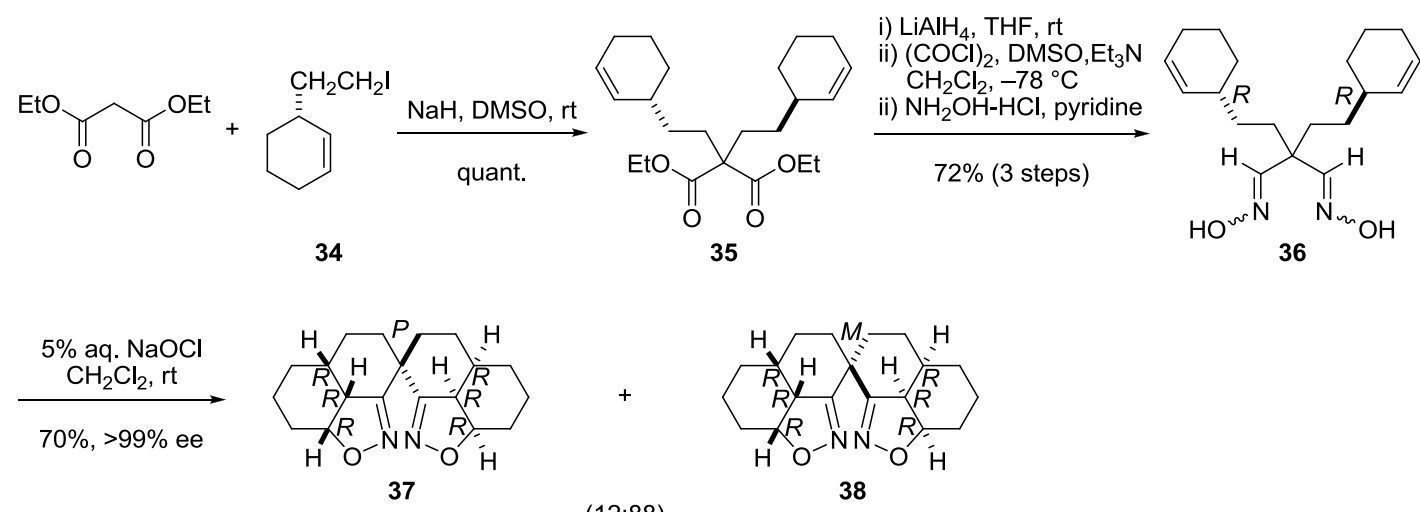

$(12: 88)$

Scheme 8: Synthesis of the polycyclic spiro bis(isoxazolines). 


\section{Review}

\section{Spiro bis(oxazoline)}

For the synthesis of spiro bis(oxazoline) ligand 49, diethyl 2,2-diallyl malonate (39) was converted to Weinreb amide 40 (Scheme 9). ${ }^{24}$ After $\mathrm{LiAlH}_{4}$ reduction followed by condensation with $(R)-\mathbf{4 2}$ in the presence of Ti $(\mathrm{OEt})_{4}$ produced $\mathbf{4 3}$. The aldehyde obtained after Swern oxidation of $\mathbf{4 3}$ was reacted with $(S)$-42 to produce meso-44. Diastereoselective 1,2-addition of vinyl lithium to meso-44 predominantly gave 45, which was treated with $\mathrm{HCl}$ and then reacted with benzoyl chloride to give the cyclization precursor $(S, S)$-46. Ring closing metathesis of tetraene $\mathbf{4 6}$ with Grubbs catalyst produced spiro amides $(M, S, S)-\mathbf{4 7}$ and $(M, R, R)-\mathbf{4 8}$. Finally, the desired ligand ( \pm )-49 was synthesized from $(M, S, S)-\mathbf{4 7}$ in $82 \%$ yield via oxazoline ring formation promoted by $N$-bromosuccinimide (NBS). This reaction proceeded with high diastereoselectivity, with no other diastereomer being observed. After separation by using a chiral stationary phase column [Daicel Chiralpak AD $(\varnothing 2 \mathrm{~cm} \times 25 \mathrm{~cm})$ ], the enantiopure 49 was used in the $\mathrm{Cu}$-catalyzed glyoxylate-ene and Henry reactions.
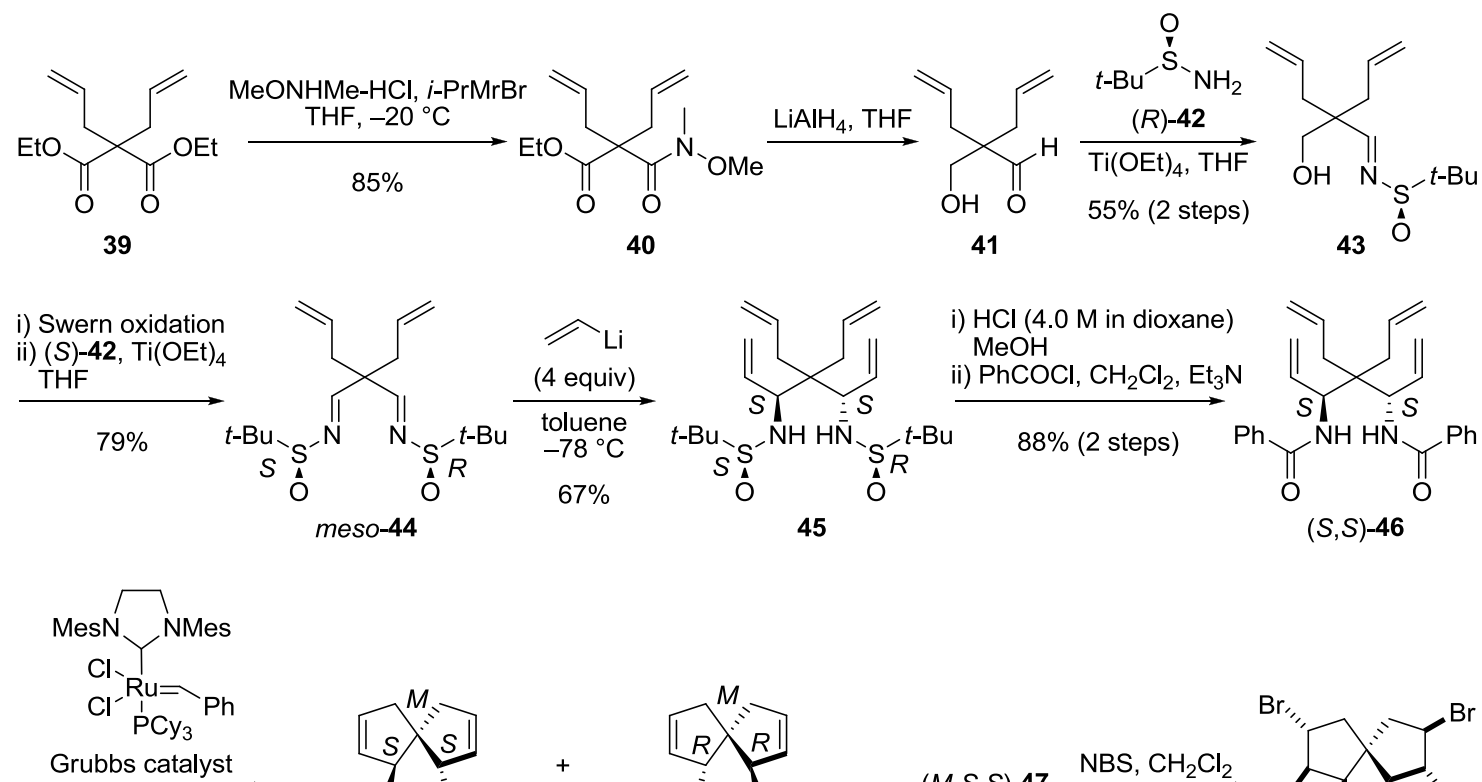

toluene, $90^{\circ} \mathrm{C}$
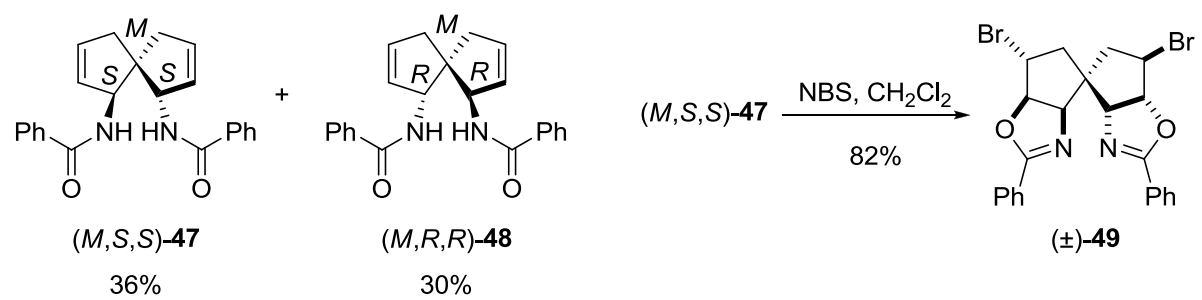

$( \pm)-49$

Scheme 9: Synthesis of spiro bis(oxazoline).

\section{Spiro bis(pyrazole)}

Furthermore, spiro bis(pyrazole) ligand $\mathbf{5 1}$ was synthesized by Sasai et al (Scheme 10). ${ }^{25}$ Heating of a mixture of spiro[4.4]nonane-1,6-dione and $N, N$-dimethylformamide dimethyl acetal produced dione $\mathbf{5 0}$. Treatment of $\mathbf{5 0}$ with an excess of hydrazine monohydrate and $\mathrm{AcOH}$ produced ligand $( \pm)-\mathbf{5 1}$. Optically pure 51 was obtained by separation with a chiral stationary phase column [Daicel Chiralpak AD ( $\varnothing 2 \mathrm{~cm}$ $\times 25 \mathrm{~cm})]$ and used in the $\mathrm{Cu}$-catalyzed asymmetric glyoxylate-ene reaction. 
<smiles>O=C1CCCC12CCCC2=O</smiles>

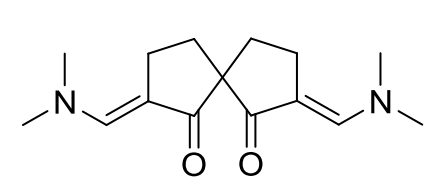

50

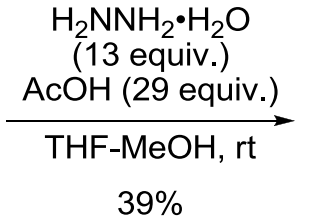

$39 \%$

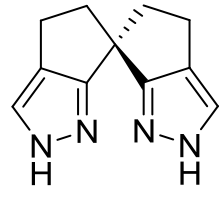

51

Scheme 10: Synthesis of spiro bis(pyrazole).

\section{Spiro bis(isoxazole)}

Designing of ligand $\mathbf{5 6}$ having isoxazole rings led to the synthesis of dioxime $\mathbf{5 5}$ using alkynyl halide $\mathbf{5 2}$ by following similar strategy of the SPRIX synthesis (Scheme 11). ${ }^{26}$ Intramolecular double nitrile oxide cycloaddition of dioxime $\mathbf{5 5}$ produced $\mathbf{5 6}$ in 40-51\% overall yield. After separation by using a chiral stationary phase column chromatography [Daicel Chiralpak AD $(\varnothing 2 \mathrm{~cm} \times 25 \mathrm{~cm})]$, the enantiomerically pure 56a and 56b were tested for the catalytic activity in the Pd-catalyzed tandem cyclization of dialkenyl alcohols (see: Scheme 12).

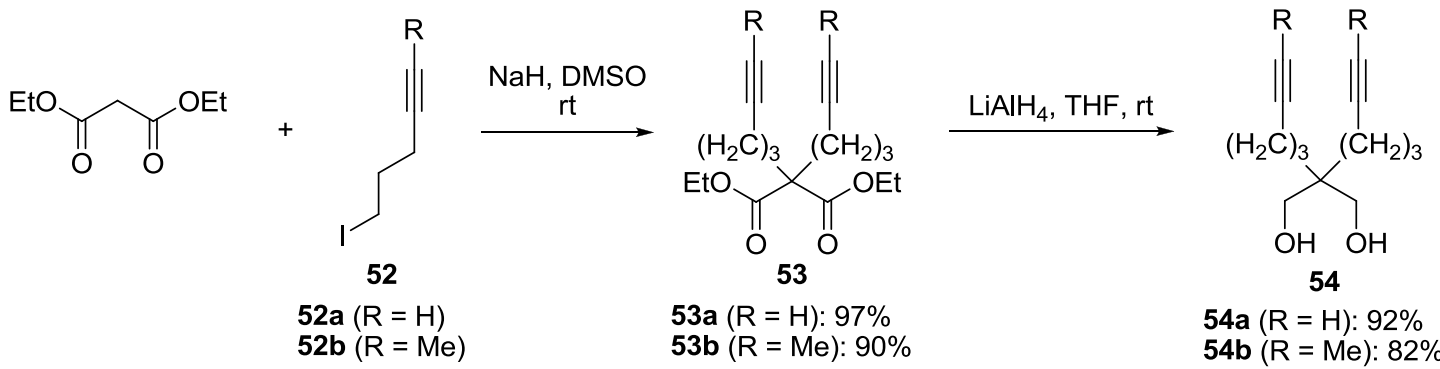

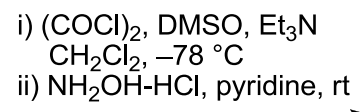

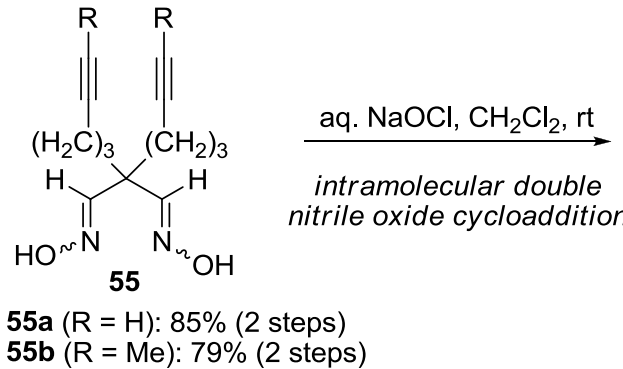

Scheme 11: Synthesis of spiro bis(isoxazole).

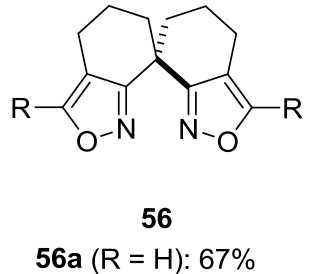

56a $(R=H): 67 \%$
56b $(R=M e): 69 \%$

\section{Spiro (isoxazoline-isoxazole)}

A weaker coordinating chiral spiro bis(isoxazoline) ligand (SPRIX) 28 restores the Lewis acidity at the metal center making it more reactive. In contrast, a more weaker coordinating chiral spiro bis(isoxazole) ligands $\mathbf{5 6}$ were found ineffective in the Pd-catalyzed tandem cyclization of the dialkenyl alcohol (Scheme 12). 
<smiles>CC(C)=CCC(CO)(CC=C(C)C)COC(C)(C)C</smiles>

57

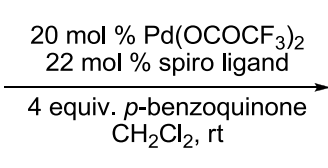

$\frac{\text { other conditions }}{(M, S, S)-i-\operatorname{Pr}-\mathrm{SPRIX} 2 \mathbf{2 8}(8 \mathrm{~h})}$
$(M, S, S)-i-\mathrm{Pr}-\mathrm{SPRIX} \mathbf{2 8 d}\left(85 \mathrm{~h}\right.$ at $\left.0^{\circ}\right)$
$(+)-56 \mathbf{a}(17 \mathrm{~h})$
$(+)-56 \mathbf{b}(7 \mathrm{~h})$

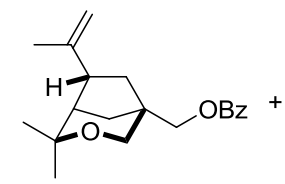

58

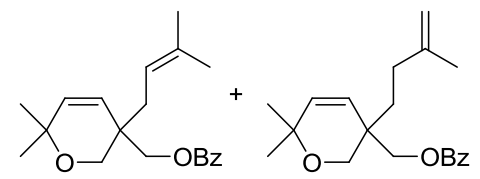

59

60

\begin{tabular}{|c|c|c|}
\hline 58 & 59 & 60 \\
\hline $42 \%, 93 \%$ ee & $15 \%$ & $17 \%$ \\
\hline $65 \%, 95 \%$ ee & $5 \%$ & $26 \%$ \\
\hline $27 \%, 56 \%$ ee & $43 \%$ & $4 \%$ \\
\hline $23 \%, 59 \%$ ee & $47 \%$ & $8 \%$ \\
\hline
\end{tabular}

Scheme 12: Pd-catalyzed tandem cyclization of the dialkenyl alcohol

We thought that a combination of weakly coordinating groups and more rigid structure would provide optimum benefit in designing a new ligand. Thus we designed a new hybrid spiro isoxazolineisoxazole ligand containing an unsymmetrical spiro backbone ${ }^{27}$ It was anticipated that in this new design of hybrid ligand, only two diastereomers would be formed and this is advantageous, since in the case of synthesis of SPRIX, three diastereomers were obtained. A computational calculation study of possible diastereomers with varying ring size such as spiro[4.4]nonane, spiro[4.5]decane, spiro[5.5] undecane and spiro[4.6] undecane using HF/6-31G* revealed that spiro[4.5]decane skeleton has the most suitable design. And, the isoxazoline and isoxazole rings fused to the 5 and 6 membered spiro rings, respectively, showed the shortest $N-N$ distance (3.35 ̊) (Figure 4).

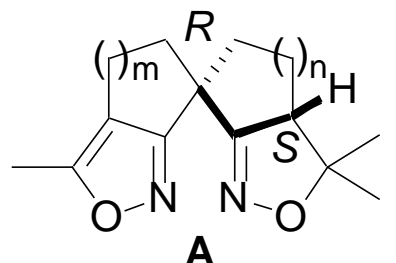

I spiro[4.4]nonan e

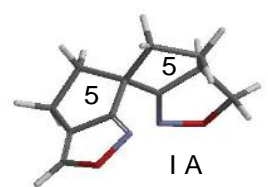

N1-N2 $3.76 \AA$

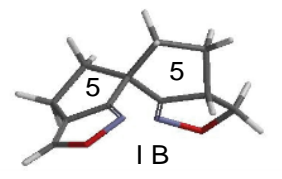

N1-N2 $4.21 \AA$

III spiro[5.5]unde cane

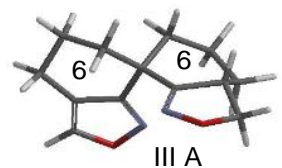

N1-N2 $3.57 \AA$

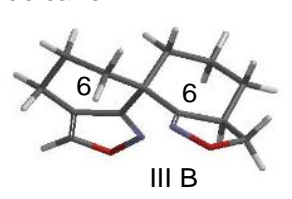

N1-N2 $3.90 \AA$

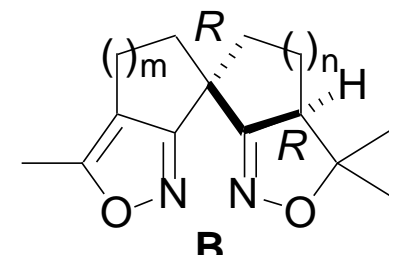

B

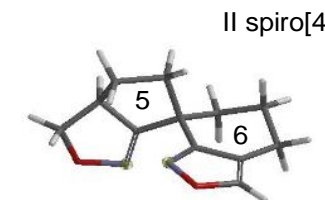

II A

N1-N2 $3.35 \AA$

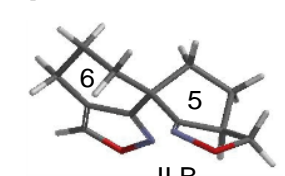

II B

N1-N2 $4.01 \AA$

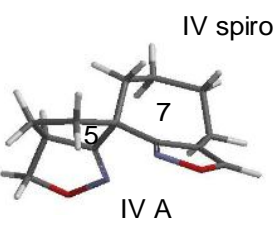

N1-N2 $3.87 \AA$

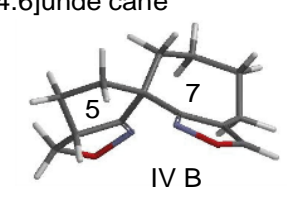

N1-N2 $4.32 \AA$

Figure 4: Optimization of the structures with various ring size.

-9. 
After structure optimization, a flexible synthetic route similar to that of SPRIX was employed for the synthesis of the hybrid spiro (isoxazoline-isoxazole) ligands 63 and 64 (Scheme 13). In the initial step, different combinations of alkenyl- and alkynyl halides were used for the alkylation of diethyl malonate to produce differentially substituted diesters 61. After successive $\mathrm{LiAlH}_{4}$ reduction, Swern oxidation, dioxime formation, followed by intramolecular double nitrile oxide cycloaddition of the dioxime $\mathbf{6 2}$ produced 63 and 64 with a high diastereoselectivity. Optically pure ligands were obtained by separation using a chiral stationary phase column chromatography [Daicel Chiralpak AD $(\varnothing 2 \mathrm{~cm} \times 25 \mathrm{~cm})]$. The relative configuration of the spiro skeleton was confirmed by X-ray analysis of 63c (Figure 5). The distance between the two nitrogens was found to be $3.71 \AA$, in a close agreement with the calculated value. The hybrid ligands $\mathbf{6 3}$ were then used in the Pd-catalyzed asymmetric tandem cyclization of $\mathbf{5 7}$. In accord with our hypothesis, the hybrid ligand 63e was found more efficient and yielded $74 \%$ of the tandem product $\mathbf{5 8}$ in $95 \%$ ee within 17 hours at $0^{\circ}$ temperature using a mixed solvent $\mathrm{CH}_{2} \mathrm{Cl}_{2} / \mathrm{MeOH}$ $(1: 1)$.

\section{Biindane-based Spiro Ligands}

\section{Spiro bisphosphinite (SpiroBIP)}

Keay et al. reported synthesis of cis,cis-2,2'-spirobiindane-1,1'-diol 70, beginning with 1-indanone (65), in overall $68 \%$ yield after four steps (Scheme 14). ${ }^{28}$ In the presence of NaH, treatment of $\mathbf{6 5}$ with diethyl carbonate produced $\beta$-keto ester 66. Alkylation of $\mathbf{6 6}$ with $\mathbf{6 7}$ gave diester $\mathbf{6 8}$, which when treated with $70 \% \mathrm{H}_{2} \mathrm{SO}_{4}$ produced dione $\mathbf{6 9}$. Reduction of $\mathbf{6 9}$ with lithium tert-butyldiisobutylaluminium hydride produced cis,cis-( \pm -70. Enatiopure $\mathbf{7 0}$ can be obtained by separation of diastereomeric monoesters formed upon treating cis,cis-( \pm -70 with (S)-2-(tert-butyldimethylsilyl)-mandeloyl chloride as a chiral auxiliary, followed by hydrolysis.

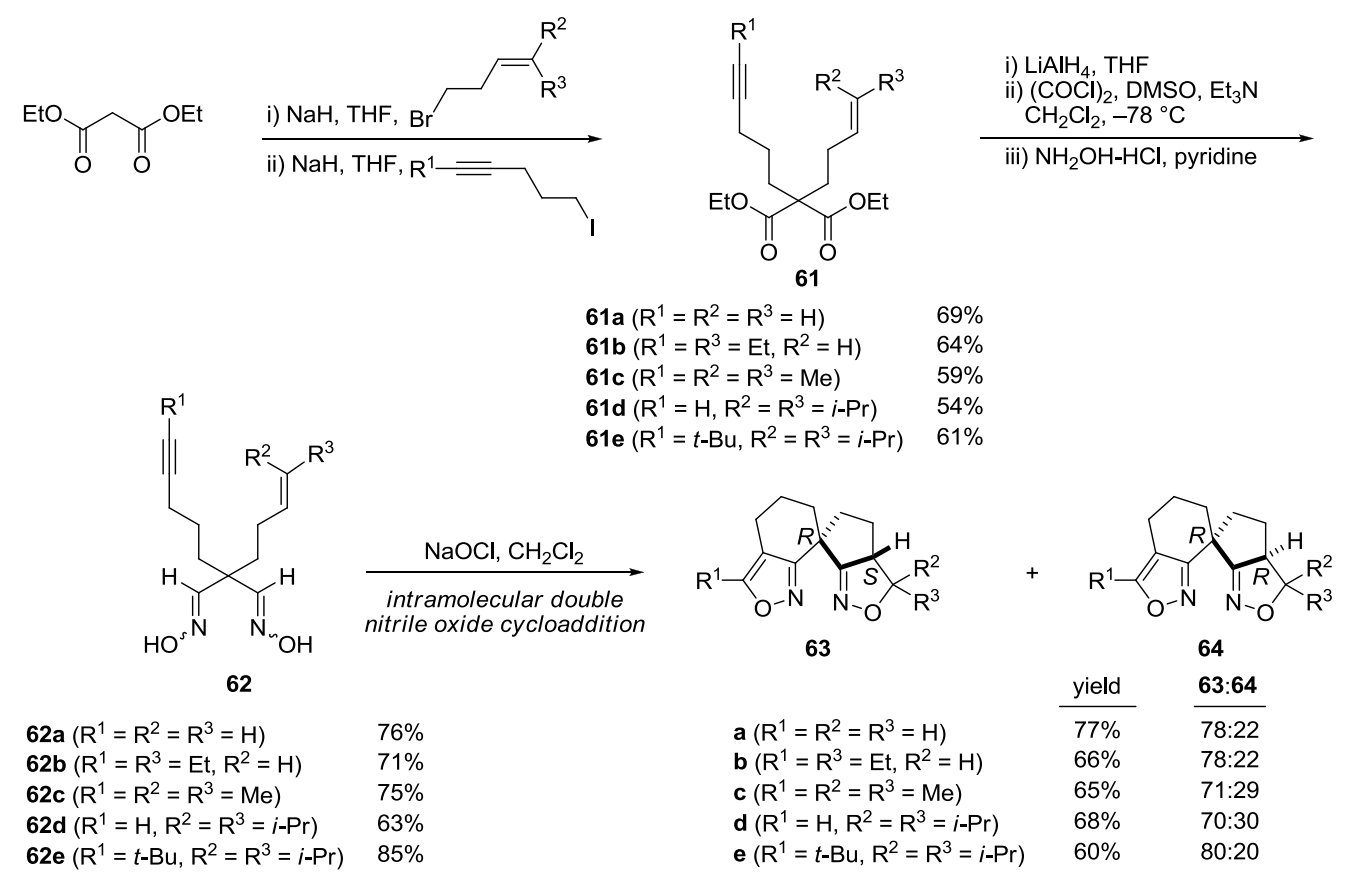

Scheme 13: Synthesis of spiro (isoxazoline-isoxazole).

$-10-$ 


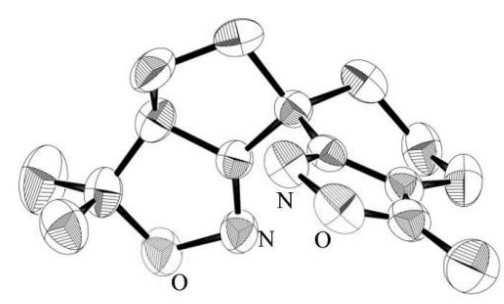

Figure 5: $X$-ray structure of $63 \mathrm{c}$ showing the spiro skeleton $(N-N=3.71 \AA)$.

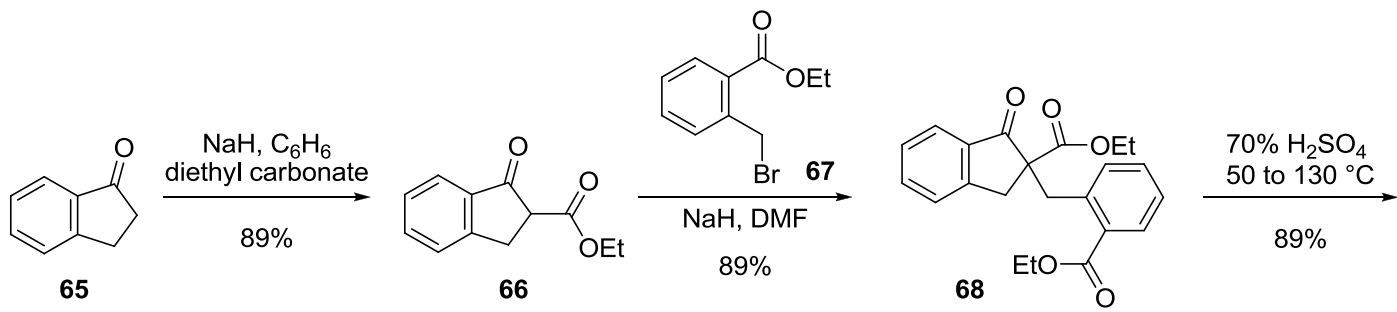

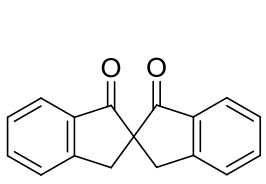

69

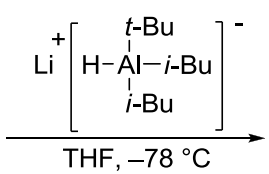

$97 \%$

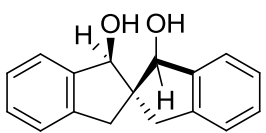

cis, cis- $( \pm)-70$

Scheme 14: Synthesis of cis,cis-2,2'-spirobiindane-1,1'-diol.

An alternative preparation of cis,cis-2,2'-spirobiindane-1,1'-dione 69 via dibenzylation of diethylmalonate followed by cyclization is reported by Burk and Harlow (Scheme 15). ${ }^{29}$ Following the

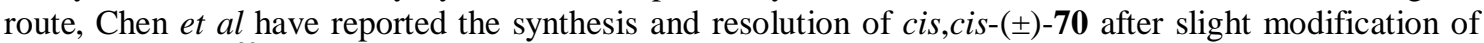
Keay's protocol. ${ }^{30}$

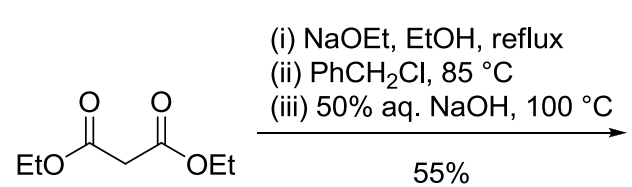

$55 \%$<smiles>O=C(O)C(Cc1ccccc1)(Cc1ccccc1)C(=O)O</smiles>

71

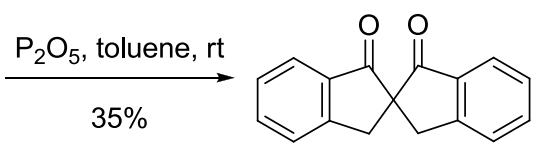

69

Scheme 15: Synthesis of cis,cis-2,2'-spirobiindane-1,1'-dione.

The enantiopure 2,2'-spirobiindane-1,1'-diol $\mathbf{7 0}$ was then converted into chiral 1,1'bis(diphenylphosphinoxy)-2,2'-spirobiindane (SpiroBIP) 72 (Scheme 16). ${ }^{30}$ This ligand was used in the $\mathrm{Rh}$-catalyzed asymmetric hydrogenation and found comparatively less efficient than SpirOP 7, perhaps due to weaker metal coordination executed by the steric hindrance of fused benzene rings. 


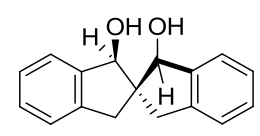

$\left(1 R, 2 R, 1^{\prime} R\right)-(-)-70$

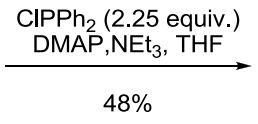

$48 \%$

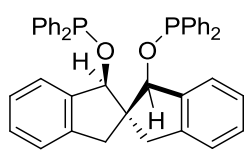

(R)-(-)-SpiroBIP 72

Scheme 16: Synthesis of SpiroBIP.

\section{1,1'-Spirobindane-7,7'-diol (SPINOL)}

In 1999, Birman et al. reported the synthesis of 1,1'-spirobiindane-7,7'-diol (SPINOL) 77a (Scheme 17). ${ }^{31}$ Condensation of $m$-anisaldehyde with acetone followed by hydrogenation produced ketone $\mathbf{7 4}$. In order to direct the bis-cyclization ortho- to the methoxy groups, the para-positions to the methoxy groups were blocked with removable $\mathrm{Br}$ substituent. Treatment of bis-brominated compound $\mathbf{7 5}$ with polyphosphoric acid underwent spiro cyclization to give 76. Debromination of $\mathbf{7 6}$ followed by demethylation produced ( \pm )-SPINOL 77a in $28 \%$ overall yield. Pure enantiomers of SPINOL can be obtained by treating ( \pm )-77a with (-)-menthyl chloroformate and $\mathrm{Et}_{3} \mathrm{~N}$ followed by hydrozinolysis of resulting diasteromers using hydrazine hydrate. ${ }^{31}$ Alternatively, $( \pm)-\mathbf{7 7 a}$ can be resolved by inclusion complexation with $N$-benzylcinchonium chloride. ${ }^{32}$

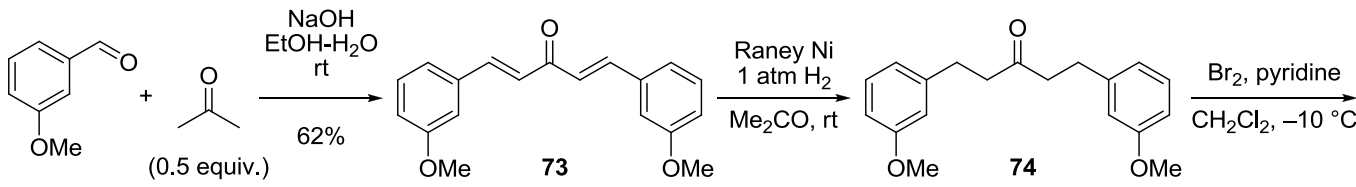

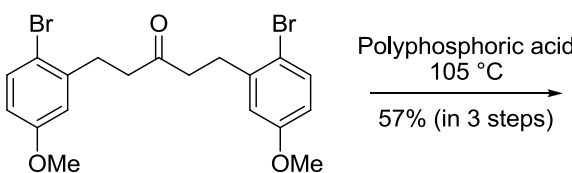

75

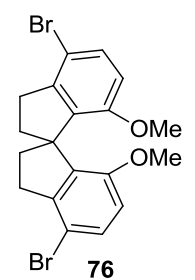

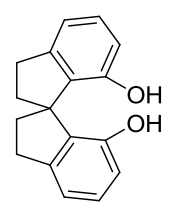

(土)-SPINOL 77a

Scheme 17: Synthesis of SPINOL.

In 2003, Zhou et al have reported synthesis 4,4'-disubstituted-SPINOL from enantiomerically pure SPINOL 77a. ${ }^{33}$ For example; $(S)-4,4^{\prime}$-dibromo-7,7'-dihydroxy-1,1'-spirobiindane (DBSPINOL) $((S)$ 77b) has been synthesized from $(S)$-77a. The protection of hydroxy groups of $(S)$-77a followed by bromination with $\mathrm{NaBr}$ in the presence of $\mathrm{H}_{2} \mathrm{O}_{2}$ produces dibromide $(S)$-76. Deprotection of hydroxyl groups in $(S)$-76 using $\mathrm{BBr}_{3}$ produces $(S)$-DBSPINOL 77b (Scheme 18).

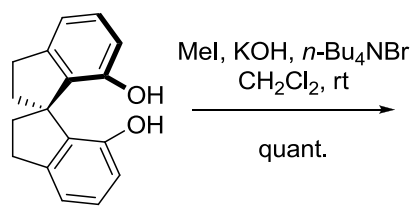

(S)-SPINOL 77a

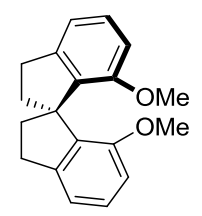

(S)-78

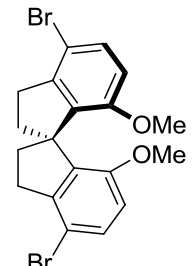

(S)-76

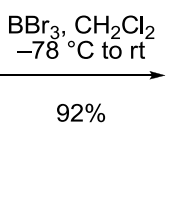

(S)-DBSPINOL 77b

Scheme 18: Synthesis of DBSPINOL.

-12- 
Later in 2004, Wan et al. have synthesized ( \pm )-DBSPINOL 77b through direct demethylation of Birmans's intermediate 76 using $\mathrm{BBr}_{3}$ and resolved with (-)-menthylchloroformate in the presence of $n$ $\mathrm{Bu}_{4} \mathrm{NBr}$ as a phase transfer catalyst, followed by hydrolysis. ${ }^{34}$ Through the replacement of two bromine atoms in diastereomer $\mathbf{7 9}$ (or 80) with appropriate electrophiles in the presence of $n$-BuLi can produce enantiopure SPINOL 77a, DISPINOL 77c and DMSPINOL 77d (Scheme 19). ${ }^{34 \mathrm{~b}}$ The SPINOL and its 4,4'-substituted derivatives in the form of their Ti-alkoxides were used as catalysts in diethylzinc additions to aromatic aldehydes. ${ }^{34 \mathrm{~b}}$

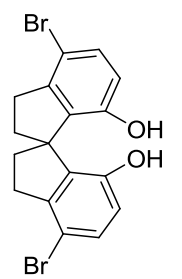

(土)-DBSPINOL 77b

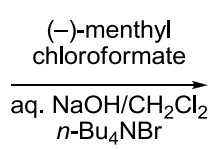

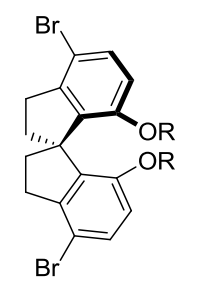

79

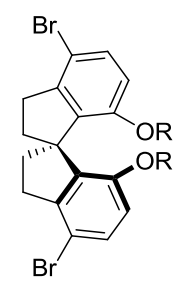

80

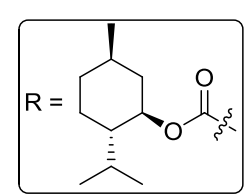

$$
\begin{array}{ll}
\text { i) } n \text {-BuLi, THF, }-78{ }^{\circ} \mathrm{C} \\
\text { ii) } \mathrm{E}^{+} \\
79 \stackrel{\text { iii) } \mathrm{KOH} / \mathrm{EtOH} \text {, reflux }}{\longrightarrow}
\end{array}
$$

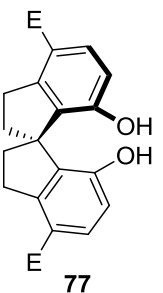

(S)-SPINOL 77a $(E=H): 97 \%$

(S)-DISPINOL $77 \mathrm{c}(\mathrm{E}=\mathrm{I}): 80 \%$

(S)-DMSPINOL 77d $(\mathrm{E}=\mathrm{Me}): 68 \%$

Scheme 19: Synthesis of enantiopure SPINOLs.

\section{Spiro monophosphite (ShiP)}

After having enantiomerically pure SPINOLs in hand, Zhou et al have synthesized a wide range of 1,1'-spirobindane-7,7'-diol-based chiral ligands. Spiro monophosphite ligands $\mathbf{8 1}$ were synthesized starting from 77a by condensation with $\mathrm{PCl}_{3}$ followed by treatment with alkoxides or condensation with dichlorophosphites in the presence of diisopropylethyl amine (Scheme 20). ${ }^{35}$ These ligands were tested in: (a) Cu-catalyzed allylic alkylation of cinnamyl bromide with diethylzinc, ${ }^{35 a}$ (b) Pd-catalyzed hydrovinylation of styrene with ethylene, ${ }^{35 \mathrm{~b}}$ and (c) Rh-catalyzed addition of arylboronic acids to aldehydes. $^{35 \mathrm{c}}$

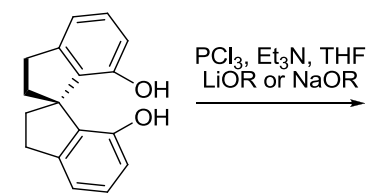

(R)-SPINOL 77a

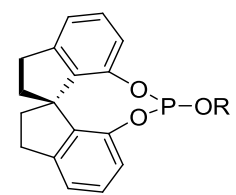

$(R)-81$

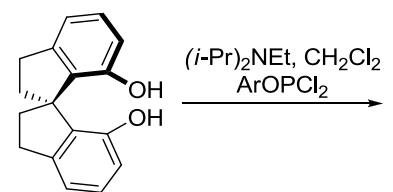

(S)-SPINOL 77a

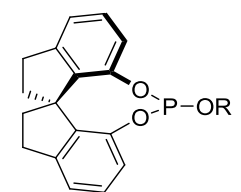

(S)-81

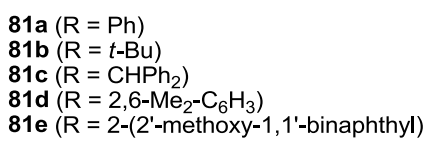

$81 f\left(\mathrm{R}=2-\mathrm{MeO}-\mathrm{C}_{6} \mathrm{H}_{4}\right)$

81g $\left(\mathrm{R}=4-\mathrm{MeO}-\mathrm{C}_{6} \mathrm{H}_{4}\right)$

$81 h(R=1$-naphthyl)

81i ( $R=2$-naphthyl)

Scheme 20: Synthesis of spiro monophosphites. 


\section{Review}

\section{Spiro phosphoramidite (SIPHOS)}

Chiral monodentate spiro phosphoramidite ligands 82 were synthesized from the corresponding enantiomerically pure SPINOLs either by heating with hexamethylphosphorus triamide or condensation with $\mathrm{PCl}_{3}$ followed by treatment with the lithium dialkylamide (Scheme 21). ${ }^{33,36}$ These ligands were used in the asymmetric hydrogenation, ${ }^{33,36 a, 36 \mathrm{~d}}$ hydrosilylation, ${ }^{37}$ hydrovinylation, ${ }^{35 \mathrm{~b}, 38}$ allylic alkylation, ${ }^{35 \mathrm{a}}$ Michael reaction, ${ }^{36 \mathrm{c}}$ Pouson-Khand reaction ${ }^{39}$ and desymmetrization of meso-oxabicyclic alkenes. ${ }^{40}$

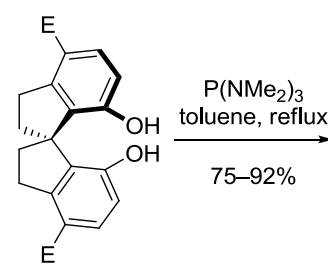

(S)-SPINOL or it's 4,4'-derivative

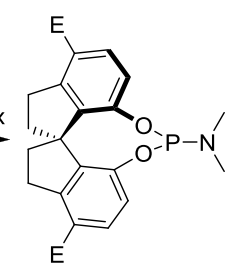

$(S)-82$

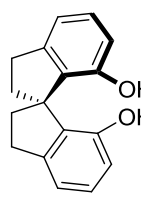

(S)-77a
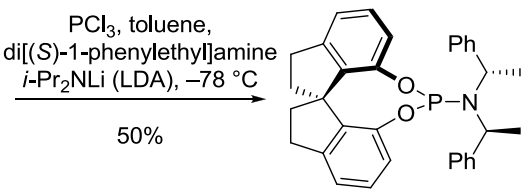

$(S, S, S)-82 \mathbf{e}($ SIPHOS-PE)

(S)-82a (SIPHOS-Me) $(\mathrm{E}=\mathrm{H})$

(S)-82b (DiBr-SIPHOS) $(\mathrm{E}=\mathrm{Br})$

(S)-82c (DiPh-SIPHOS) (E = Ph)

(S)-82d (DiMeO-SIPHOS) $(\mathrm{E}=\mathrm{MeO})$

Scheme 21: Synthesis of spiro phosphoramidites.

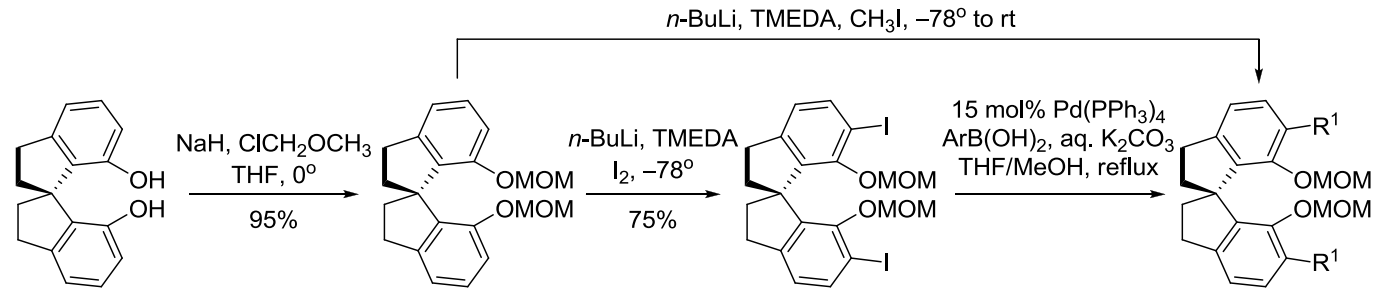

$(R)$-SPINOL 77a
83
84
85

85a $\left(R^{1}=M e\right): 79 \%$ from 83 85b $\left(R^{1}=P h\right): 94 \%$ from 84 85c $\left(R^{1}=X y l\right): 77 \%$ from 84

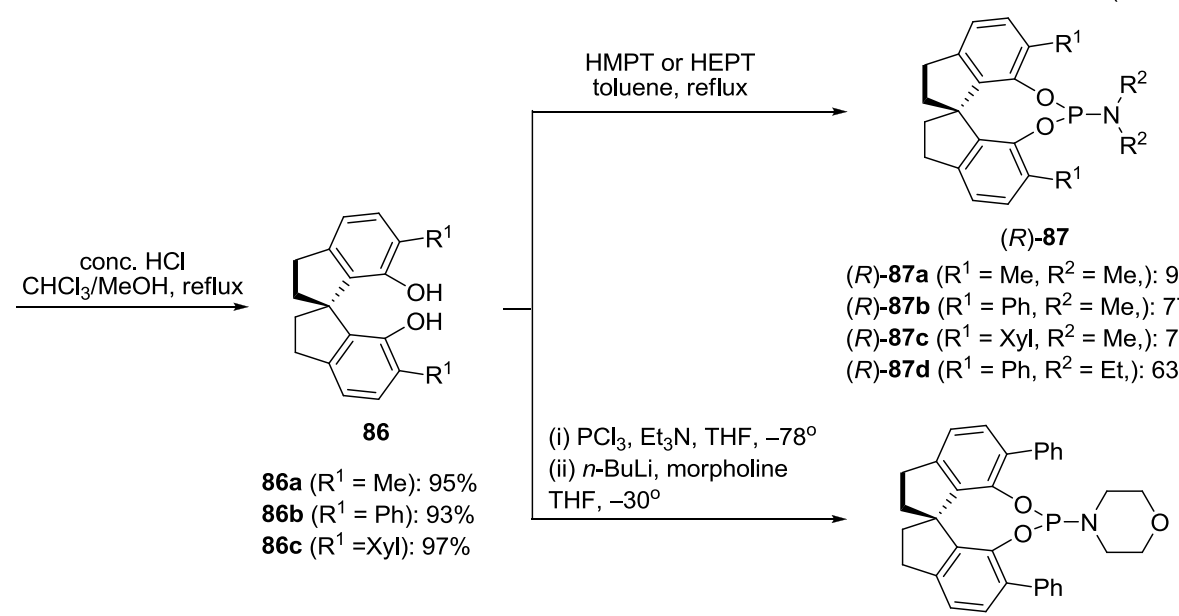

(R)-87e: $62 \%$

Scheme 22: Synthesis of 6,6'-disubstituted spirobiindane phosphoramidites. 
The 6,6'-disubstituted spirobiindane phosphoramidites ligands 87 were also synthesized by Zhou et al (Scheme 22). ${ }^{41}$ First the OH groups of enantiomerically pure $(R)$-SPINOL 77a were protected with methoxymethane. Iodination of $\mathbf{8 3}$ using bases $n$-BuLi and tetramethylethylenediamine (TMEDA) followed by Suzuki coupling installed the aryl groups at 6 and 6' positions as in structure 85, while methyl groups at the same positions were installed by direct methylation of $\mathbf{8 3}$ using methyl iodide. Deprotection of the hydroxy groups produced 6,6'-disubstituted SPINOL 86. The required 6,6'disubstituted spirobiindane phosphoramidite ligands were synthesized either by heating with hexamethylphosphorous triamide (HMPT) or hexaethylphosphorous triamide (HEPT) or condensation with $\mathrm{PCl}_{3}$ followed by treatment with the lithiated amine. These ligands were used in the first $\mathrm{Ni}$ catalyzed asymmetric reductive coupling of 1,3-dienes and aldehydes to yield chiral bishomoallylic alcohols.

\section{Spiro phosphonite (FuP)}

Zhou et al have synthesized chiral spiro phosphonites $(S)$-88 from $(S)$-SPINOL 77a by treating with the corresponding dichlorophosphine in the presence of $\mathrm{Et}_{3} \mathrm{~N}$ and used in the $\mathrm{Rh}$-catalyzed asymmetric hydrogenation (Scheme 23). ${ }^{42}$

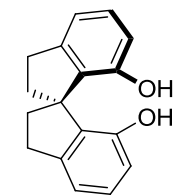

(S)-SPINOL 77a

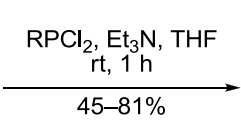

(S) $-88 \mathbf{a}(\mathrm{R}=\mathrm{Ph})$
(S) $-88 \mathrm{~b}(\mathrm{R}=4-\mathrm{Me}-\mathrm{C}$

(S)-88b $\left(\mathrm{R}=4-\mathrm{Me}^{-} \mathrm{C}_{6} \mathrm{H}_{4}\right)$

(S)-88c $\left(\mathrm{R}=4-\mathrm{MeO}-\mathrm{C}_{6} \mathrm{H}_{4}\right)$
(S) $-88 \mathrm{~d}\left(\mathrm{R}=4-\mathrm{Cl}-\mathrm{C}_{6} \mathrm{H}_{4}\right)$

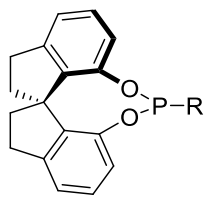

(S)-88

(S)-88e $\left(\mathrm{R}=4-\mathrm{CF}_{3}-\mathrm{C}_{6} \mathrm{H}_{4}\right)$

(S) $-88 \mathrm{f}(\mathrm{R}=\mathrm{Me})$

(S)-88g $(\mathrm{R}=i-\mathrm{Pr})$

(S)-88h ( $\mathrm{R}=t$-Bu)

Scheme 23: Synthesis of spiro phosphonites.

\section{Spiro phospholane (SITCP)}

Zhou et al. have synthesized chiral monodentate phospholane ligand (SITCP) 93 from enantiomerically pure SPINOL in six steps (Scheme 24). ${ }^{43}$<smiles>Oc1cccc2c1C1(CCC2)Cc2cccc(O)c21</smiles>

(R)-SPINOL 77a

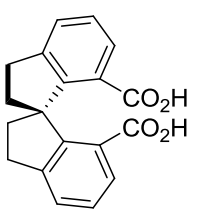

$(R)-91$
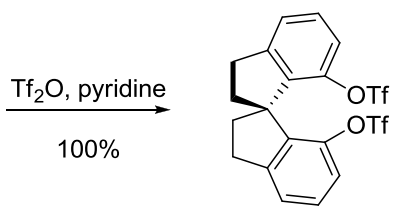

$(R)-89$

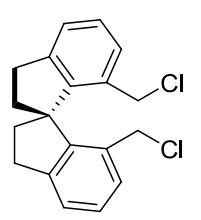

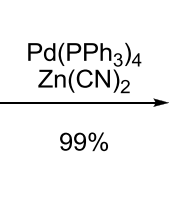

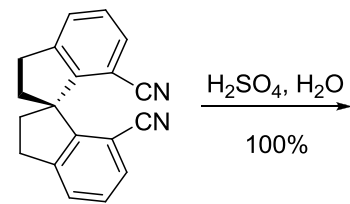

$(R)-90$
$(R)-92$

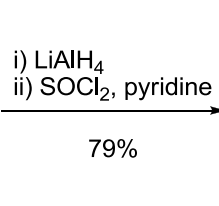

Scheme 24: Synthesis of spiro phospholane.

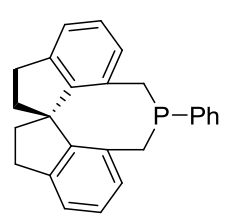

$(R)-93$

$-15-$ 
$(R)$-77a was converted into ditriflate 89 by ligand exchange and then cynated with $\mathrm{Zn}(\mathrm{CN})_{2}$ catalyzed by $\mathrm{Pd}\left(\mathrm{PPh}_{3}\right)_{4}$ to produce dinitrile $\mathbf{9 0}$. Hydrolysis of 90 produced diacid 91 , which after $\mathrm{LiAlH}_{4}$ reduction followed by $\mathrm{SOCl}_{2}$ treatment produced dichloride $\mathbf{9 2}$. The condensation of $\mathbf{9 2}$ with phenylphosphine gave phenylphospholane $(R)-93$. Spiro phospholane ligand is used in the Pd-catalyzed enantiselective allylations of aromatic, heteroaromatic and aliphatic aldehydes with allylic alcohols.

\section{Spiro diphosphine (SDP)}

Chiral diphosphine ligands are most popular in asymmetric catalysis. The first example of chiral diphosphine ligands with a spiro skeleton has been reported by Zhou et al (Scheme 25). ${ }^{44}$ Ditriflate $(S)-89$, obtained from (S)-SPINOL 77a (see: Scheme 24), monophosphinylated with diarylphosphine oxide in the presence of $\mathrm{Pd}(\mathrm{OAc})_{2}$-dppb (dppb = 1,4-bis(diphenylphosphino)-butane) followed by reduction with trichlorosilane to produce phosphine monotriflate 95. The second phosphine group was introduced using the same conditions as for the first by phosphinylation of $\mathbf{9 5}$ followed by reduction to give chiral spiro diphosphines (S)-96. Ruthenium catalyst prepared from the spiro diphosphine ligands were used in the asymmetric hydrogenations of aromatic, heteroaromatic, and $\alpha, \beta$-unsaturated ketones. ${ }^{44 a}$ Spiro diphosphine ligands were further utilized in the Pd-catalyzed allylic alkylation of ( \pm )-1,3-diphenyl-2propenyl acetate. ${ }^{4 \mathrm{~b}}$

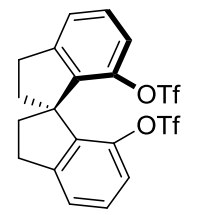

$(S)-89$

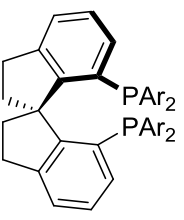

$(S)-96$

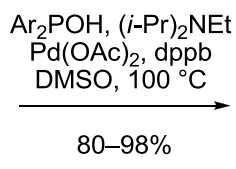

(S)-96a (SDP) $(\mathrm{Ar}=\mathrm{Ph})$

(S)-96b (xyl-SDP) $\left(\mathrm{Ar}=3,5-\mathrm{Me}_{2}-\mathrm{C}_{6} \mathrm{H}_{3}\right)$

(S)-96c (Tol-SDP) $\left(\mathrm{Ar}=4-\mathrm{Me}-\mathrm{C}_{6} \mathrm{H}_{4}\right)$

(S)-96d (An-SDP) $\left(\mathrm{Ar}=4-\mathrm{MeO}-\mathrm{C}_{6} \mathrm{H}_{4}\right)$

(S)-96e (DMM-SDP) ( $\left.\mathrm{Ar}=3,5-\mathrm{Me}_{2}-4-\mathrm{MeO}-\mathrm{C}_{6} \mathrm{H}_{2}\right)$

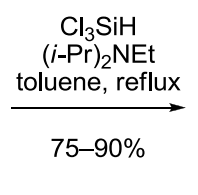

(S)-94

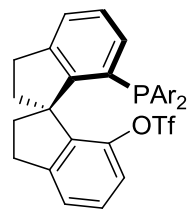

(S)-95 i) $\mathrm{Ar}_{2} \mathrm{POH}, \mathrm{Pd}(\mathrm{OAc})_{2}, \mathrm{dppb}$ $(i-\mathrm{Pr})_{2} \mathrm{NEt}, \mathrm{DMSO}, 100^{\circ} \mathrm{C}$

ii) $\mathrm{Cl}_{3} \mathrm{SiH},(i-\mathrm{Pr})_{2} \mathrm{NEt}$ toluene, reflux

$64-79 \%$

Scheme 25: Synthesis of spiro diphosphines.

\section{Spiro phosphine-oxazoline (SIPHOX)}

Zhou et al further reported spiro phosphine-oxazoline ligands $\mathbf{1 0 0}$ (Scheme 26) ${ }^{45}$ In the presence of 1,3-bis(diphenylphosphino)-propane (dppp) ligand, the Pd-catalyzed carbonylation of optically pure $\mathbf{9 5}$ produced esters $\mathbf{9 7}$, which after hydrolysis followed by condensation with enatiomerically pure amino alcohols in the presence of 1-hydroxylbenzotriazole (HOBt) and $N, N^{\prime}$-dicyclohexylcarbodiimide (DCC) gave amides 99. Cyclization of 99 produced spiro phosphine-oxazoline ligands 100. Mixing of $[\mathrm{Ir}(\mathrm{COD}) \mathrm{Cl}]_{2} \quad\left(\mathrm{COD}=1,5\right.$-cyclooctadiene), ligand $\mathbf{1 0 0}$ and $\mathrm{NaBARF} \cdot 3 \mathrm{H}_{2} \mathrm{O}$ (BARF = tetrakis-3,5bis(trifluoromethyl)-phenylborate) in the ratio $0.5: 1: 1.5$ produced the cationic iridium complex 101 . The Ir-SIPHOX complexes 101 catalyzed asymmetric hydrogenation of acyclic $N$-aryl ketimines under ambient hydrogen pressure providing chiral amines in excellent enatioselectivity. More recently, the application of Ir-SIPHOX complexes has found in enantioselective hydrogenations of $\alpha$-aryloxy and $\alpha$ alkoxy-substituted $\alpha, \beta$-unsaturated carboxylic acids to produce $\alpha$-hydroxy acids, after deprotection. ${ }^{46}$ 


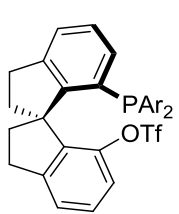

(S)-95

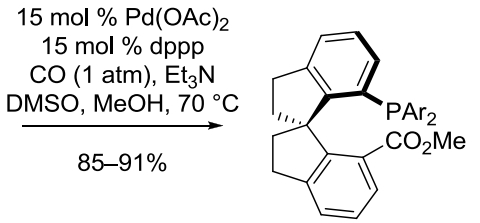

(S)-97

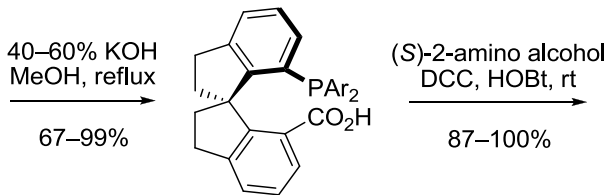

(S)-98

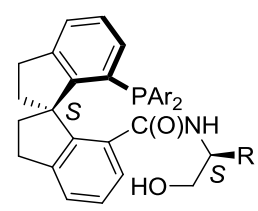

(S, S)-99

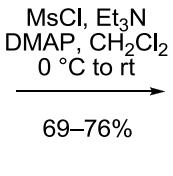

$9-76 \%$

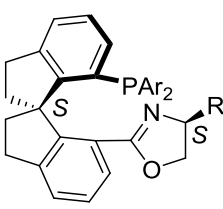

$(S, S)-100$

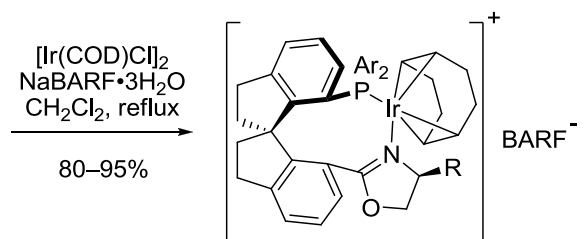

(S,S)-101

$(S, S)-101 \mathrm{a}(\mathrm{Ar}=\mathrm{Ph}, \mathrm{R}=i-\mathrm{Pr})$

$(S, S)-101 b(A r=P h, R=P h)$

$(S, S)-101 \mathrm{c}(\mathrm{Ar}=\mathrm{Ph}, \mathrm{R}=\mathrm{Bn})$

$(S, S)-101 d\left(\mathrm{Ar}=4-\mathrm{MeO}-\mathrm{C}_{6} \mathrm{H}_{4}, \mathrm{R}=\mathrm{Bn}\right)$

$(S, S)-101 e\left(A r=3,5-\mathrm{Me}_{2}-\mathrm{C}_{6} \mathrm{H}_{3}, \mathrm{R}=\mathrm{Bn}\right)$

$(S, S)-101 f\left(A r=3,5-t-B_{2}-C_{6} H_{3}, R=B n\right)$

Scheme 26: Synthesis of spiro phosphine-oxazolines.

\section{Spiro aminophosphine (SpiroAP)}

Optically pure $(R)$-SPINOL 77a was converted into spiro aminophosphine ligands via bisarylphosphino-7'-caboxy-1,1'-spirobiindannes $(R)-\mathbf{9 8}$, a key intermediate in the synthesis of spiro phosphine-oxazolines (see: Scheme 26) ${ }^{47}$ The Schmidt reaction of phosphino acids $(R)-\mathbf{9 8}$ produced the spiro aminophosphine ligands 102 (Scheme 27). These ligands were used in the Ir-catalyzed hydrogenation of $\alpha$-arylmethylene cycloalkanones.

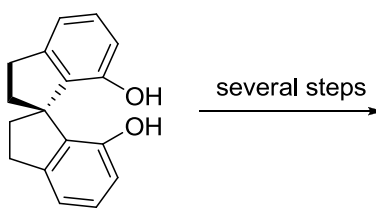

$(R)$-SPINOL 77a

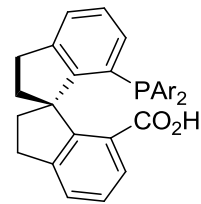

$(R)-98$

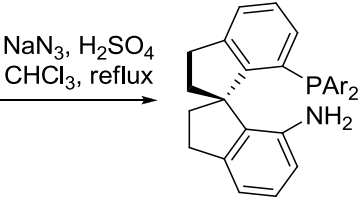

$(R)-102$

$$
\begin{aligned}
& (R)-102 \mathrm{a}(\mathrm{Ar}=\mathrm{Ph}): 98 \% \\
& (R)-102 \mathrm{~b}\left(\mathrm{Ar}=4-\mathrm{Me}-\mathrm{C}_{6} \mathrm{H}_{4}\right): 80 \% \\
& (R)-102 \mathrm{c}\left(\mathrm{Ar}=4-\mathrm{MeO}^{-} \mathrm{C}_{6} \mathrm{H}_{4}\right): 80 \% \\
& (R)-102 \mathrm{~d}\left(\mathrm{Ar}=3,5-\mathrm{Me}_{2}-\mathrm{C}_{6} \mathrm{H}_{3}\right): 87 \% \\
& (R)-102 \mathrm{e}\left(\mathrm{Ar}=3,5-t-\mathrm{Bu}_{2}-\mathrm{C}_{6} \mathrm{H}_{3}\right): 91 \% \\
& (R)-102 \mathrm{fr}\left(\mathrm{Ar}=4-\mathrm{MeO}-3,5-t-\mathrm{Bu}_{2}-\mathrm{C}_{6} \mathrm{H}_{2}\right): 90 \%
\end{aligned}
$$

Scheme 27: Synthesis of spiro aminophosphines.

\section{Spiro bispyridyl diamide (SIPAD) and spiro bisquinolyl diamide (SIQAD)}

Zhou et al synthesized chiral spiro bispyridyl diamide (SIPAD) 104a and spiro bisquinolyl diamide (SIQAD) 104b having pyridine and quinoline as coordinating units, respectively (Scheme 28). ${ }^{48}$ Curtius rearrangement of $(S)-\mathbf{9 1}$ (see: Scheme 24 ) produced diamine $(S)$-103, which was treated with picolinic acid or quinoline-2-carboxylic acid in the presence of dicyclohexylcarbodiimide and $N, N$-dimethyl-4diaminopyridine to give corresponding ligands $(S)$-104a or $(S)$-104b, respectively. The cobalt complexes prepared in situ from $\mathrm{Co}(\mathrm{OAc})_{2}$ and SIPAD 104a showed a moderate enantioselectivity in the asymmetric Michael addition of malonates to chalcone derivatives. 


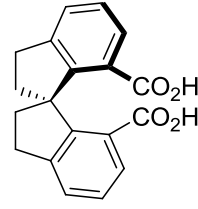

(S)-91

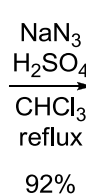

$92 \%$

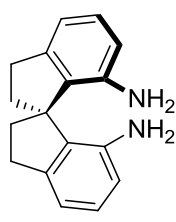

(S)-103

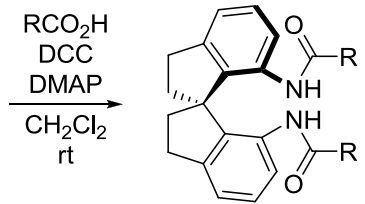

(S)-104

(S)-104a (SIPAD) (R = 2-pyridyl) $\quad 93 \%$

(S)-104b (SIQAD) ( $R=2$-quinolyl) $\quad 92 \%$

Scheme 28: Synthesis of SIPAD and SIQAD.

\section{Spiro bis(oxazoline) (SpiroBOX)}

Zhou et al have reported synthesis of spiro bis(oxazoline) ligands 106 (Scheme 29). ${ }^{49}$ Enantiomerically pure dicarboxylic acid 91 on treating with optically active amino alcohols in the presence of HOBt and DCC gave amides 105, which was subjected to oxazoline ring formation and produced 106. The efficiency of the ligands was evaluated in the Cu-catalyzed asymmetric cyclopropanation of styrene derivatives, allylic oxidation of cyclic alkenes and insertion of carbenoids into $\mathrm{O}-\mathrm{H}$ and $\mathrm{N}-\mathrm{H}$ bonds. ${ }^{50}$ Later Ma et al have synthesized more bulkier spiro bis(oxazoline) ligands with $\alpha$-naphthylmethyl and $\beta$-naphtylmethyl substituents following Zhou's protocol and used in the Pdcatalyzed enantioselective cyclization of allenyl hydrazines with aromatic iodides and enantioselective cyclization of allenes with ortho-aminoiodobenzenes. ${ }^{51}$

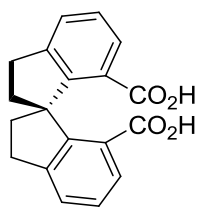

(R)-91

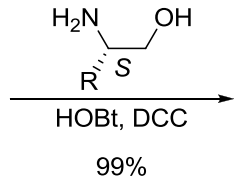

$99 \%$

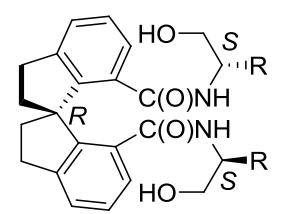

$(R, S, S)-105$
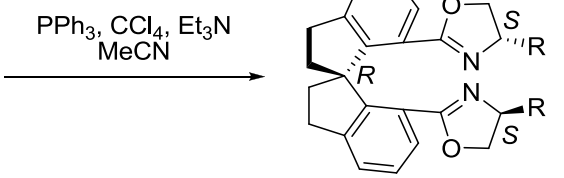

$(R, S, S)-106$

$(R, S, S)-106 \mathbf{a}(\mathrm{R}=\mathrm{Ph}) \quad 93 \%$ $(R, S, S)-106 \mathrm{~b}(\mathrm{R}=\mathrm{Bn}) \quad 97 \%$ $(R, S, S)-106 \mathrm{c}(\mathrm{R}=i-\mathrm{Pr}) \quad 91 \%$

Scheme 29: Synthesis of spiro bis(oxazoline).

\section{Bioxanthene-based Spiro Phosphoramidite Ligands}

An another variety of chiral phosphoramidite ligands 110 with 9,9'-spirobixanthene backbone was reported by Zhang et al. ${ }^{52}$ Starting from 3-phenoxyanisole (107), symmetric ketone 108 was prepared by linking 2 equivalents of lithiated $\mathbf{1 0 7}$ with methyl chloroformate (Scheme 30). Treatment of $\mathbf{1 0 8}$ with $\mathrm{AlCl}_{3}$ promoted the Friedel-Crafts alkylation as well as deprotection of methyl ether producing racemic9,9'-spriobixanthene-1,1'-diol ( \pm -109. Co-crystallization of $( \pm)$-109 using $N$-benzylcinchonidium chloride gave $(R)-\mathbf{1 0 9}$, while $(S)-\mathbf{1 0 9}$ was obtained from the mother liquor by co-crystallization with $N$ benzylquininium chloride. Treatment of $(R)$-109 with HMPT or HEPT produced $(R)-\mathbf{1 1 0 a}$ or $(R)-\mathbf{1 1 0 b}$, respectively. Ligands $(R)$-110c and $(R, S, S)$-110d were prepared by reacting the starting amine sequentially with equivalent amounts of $n-\mathrm{BuLi}, \mathrm{PCl}_{3}$ and then $(R)-\mathbf{1 0 9}$. The efficiency of the ligands in asymmetric catalysis has demonstrated in the $\mathrm{Rh}$-catalyzed hydrogenation reactions ${ }^{52 \mathrm{a}}$ and the $\mathrm{Cu}-$ catalyzed conjugate addition of diethylzinc to cyclic enones. ${ }^{52 \mathrm{~b}}$ 


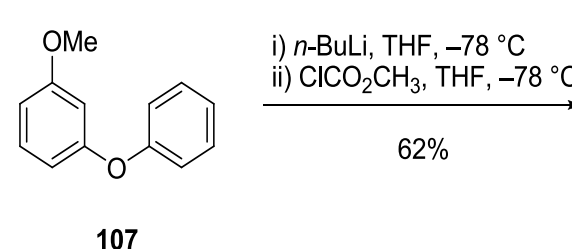

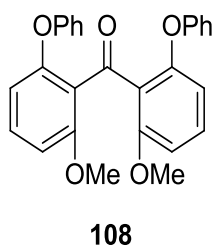

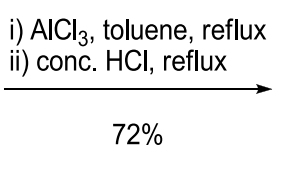

108

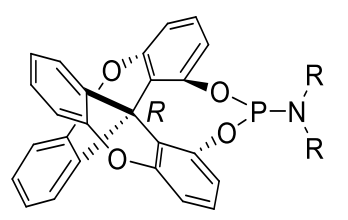

$(R)-110$

$(R)-110 \mathrm{a}(\mathrm{R}=\mathrm{Me}) \quad 47 \%$ $(R)-110 \mathrm{~b}(\mathrm{R}=\mathrm{Et}) \quad 27 \%$

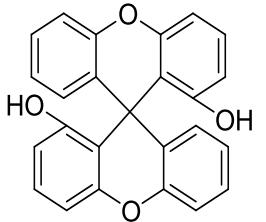

$( \pm)-109$

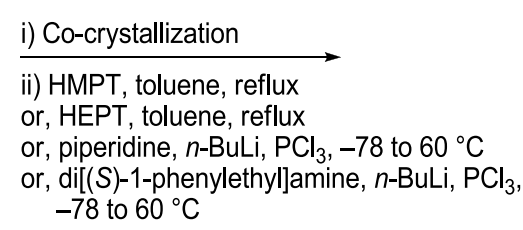

Scheme 30: Synthesis of 9,9'-spirobioxanthene-based phosphoramidites.

\section{Bifluorene-based Spiro Diphosphine Ligands (SFDP)}

A new variety of spirobifluorene-based diphosphine ligands 121 was reported by Zhou et al (Scheme 31). ${ }^{53}$ Kumada coupling product of 1,2-dibromobenzene with the Grignard reagent of 3-bromoanisole was treated with dimethyl carbonate in the presence of $n$-BuLi to produce ketone 112. Bromination followed by cyclization with methane sulphonic acid provided the 9,9'-spirobifluorene compound 114. Debromination by $\mathrm{Pd} / \mathrm{C}$-catalyzed hydrogenation followed by demethylation yielded 9,9'spirobifluorene-1,1'-diol (SBFOL) 116 in $27 \%$ overall yield. Inclusion resolution with $(2 R, 3 R)$-2,3dimethoxy- $N, N, N$ ', $N$ '-tetracyclohexyl succinamide provided optically pure $(R)$-SBFOL. ${ }^{53 a}$ The precursor was converted into the ditriflate $(R)$-117. Ni-catalyzed direct diphosphanylation with diarylphosphanes was failed, hence, a stepwise Pd-catalyzed phosphanylation with diarylphosphane oxide followed by reduction with trichlorosilane were carried out to obtain the target diphosphine ligand $(R)-\mathbf{1 2 1}{ }^{53 b}$ Using the enantiopure spiro diphosphine ligands, Ru-catalysts $\mathbf{1 2 2}$ were prepared and used in the asymmetric hydrogenation of $\alpha, \beta$-unsaturated carboxylic acids. ${ }^{53 c}$

\section{Binaphthyl-based Spiro 2-(oxazolinyl)pyridine (SPYMOX)}

2-(Oxazolinyl)pyridine ligand $\mathbf{1 2 6}$ having a spiro binaphthyl backbone is recently prepared by Shibatomi et al (Scheme 32). ${ }^{54}$ Using a phase transfer catalyst, ethyl isocyanoacetate was reacted with (R)-2,2'-bis(bromomethyl)-1,1'-binaphthyl (123) followed by hydrolysis to afford ethyl ester of 1,1'binaphthyl-substituted $\alpha$-amino isobutyric acid (H-[(R)-Bin]-OEt) 124. The condensation of 124 with 2 picolinoyl chloride followed by reduction of the ethyl ester with $\mathrm{LiBH}_{4}$ produced amido alcohol 125 . After chlorination of the primary alcohol, cyclization was achieved under basic condition to give SPYMOX $(R)$-126. This ligand was used in the Pd-catalyzed asymmetric allylic alkylation ${ }^{54 a}$ and the $\mathrm{Cu}-$ catalyzed gem-chlorofluorination of active methylene compounds. ${ }^{54 \mathrm{~b}}$ 


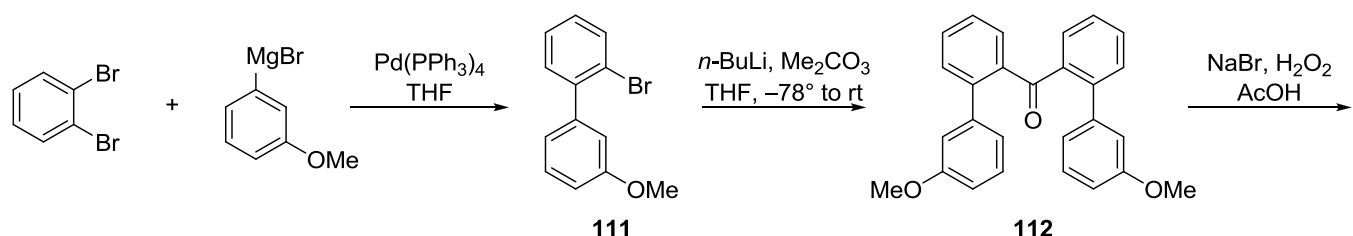<smiles>COc1ccc(Br)c(-c2ccccc2C(=O)c2ccccc2-c2ccc(Br)cc2Br)c1</smiles>

113

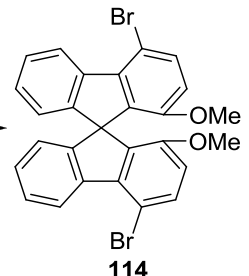

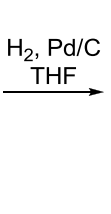

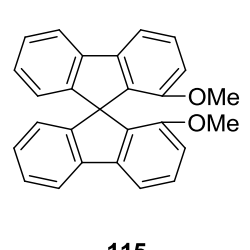

115

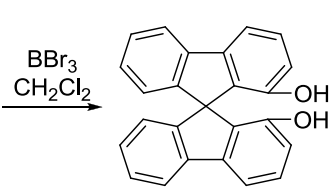

SBFOL 116 ( $27 \%$ in 6 steps)

Inclusion resolution using $(2 R, 3 R)$-2,3-dimethoxy$N, N, N^{\prime}, N^{\prime}$-tetracyclohexyl succinamide, then

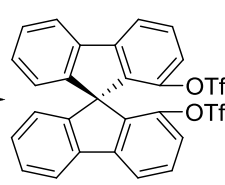

$(R)-117$

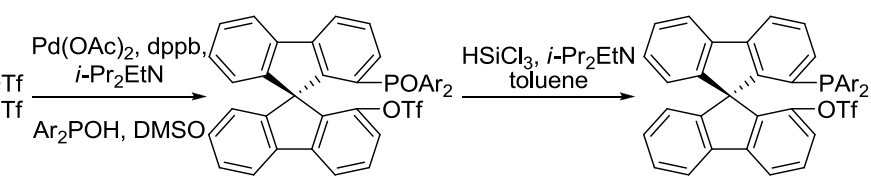

$(R)-118$
$(R)-119$

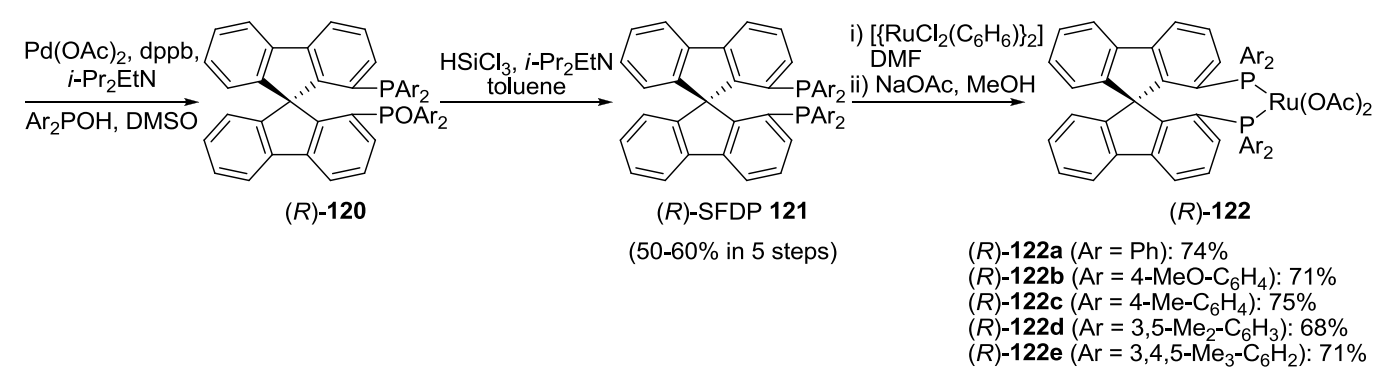

Scheme 31: Synthesis of bifluorene-based spirodiphosphines ligands and their ruthenium complexes.<smiles>BrCc1ccc(CBr)c(-c2c(CBr)ccc3ccccc23)c1Br</smiles>

123<smiles>O=C(NC1(CO)Cc2ccc3ccccc3c2-c2c(ccc3ccccc23)C1)c1ccccn1</smiles>

125

(67\%, 2 steps) (i) $\mathrm{CNCH}_{2} \mathrm{CO}_{2} \mathrm{Et}, n-\mathrm{Bu}_{4} \mathrm{~N}^{+} \mathrm{HSO} 4$ $\mathrm{K}_{2} \mathrm{CO}_{3}, \mathrm{MeCN}$ (ii) conc. $\mathrm{HCl}$, EtOH

$\underset{\text { (i) } \mathrm{SOCl}_{2}, \mathrm{CHCl}_{3}}{\text { (ii) aq. } \mathrm{NaOH} \text {, dioxane }}$

Scheme 32: Synthesis of SPYMOX. (i) 2-Picolinoyl chloride. $\mathrm{HCl}$ $\mathrm{Et}_{3} \mathrm{~N}, \mathrm{CH}_{2} \mathrm{Cl}_{2}$ (ii) $\mathrm{LiBH}_{4}$,

$\mathrm{H}-(R)$-Bin-OEt 124 (84\%, 2 steps)<smiles>c1ccc(C2=NC3(CO2)Cc2ccc4ccccc4c2-c2c(ccc4ccccc24)C3)nc1</smiles>

$(R)-126$

( $45 \%, 2$ steps) 


\section{Conclusion}

While designing and synthesis of new chiral ligands, many features are envisioned - an appropriate backbone, effective asymmetric environment, chelating sites, economic synthesis, number of diasteromers, separation, resolution and ease of ligand modification etc. - there by making the task a most challenge. The chiral diphosphine ligand with a biaryl scaffold, BINAP, is one of the most extensively used ligands in the transition-metal catalysis. In search of versatile alternative ligands, a number of research groups are extensively focusing on the development of novel chiral ligands. Among them, chiral spiro ligands with $C_{2}$-symmetrical structure are quite interesting since they have displayed unusual and unique reactivity in metal catalysis. The usefulness of chiral spiro ligands has been extensively realized after 1997, when Chan and Jiang have reported the pioneering work on the Rh-catalyzed asymmetric hydrogenation using SpirOP. About the same time, Sasai has designed and synthesized novel chiral spiro ligands bearing nitrogen containing heterocyles (such as SPRIX) and used in several oxidative cyclizations. Extensive reports on the area are due to Zhou and his co-workers. They have developed several chiral spiro ligands with a 1,1'-spirobiindane scaffold and used in new asymmetric transformations. Whereas, 2,2'-spirobiindane scaffold was incorporated by Chen in SpiroBIP. Bioxanthene-, biofluorene- and binaphthyl-based chiral spiro ligands are synthesized by Zhang, Zhou and Shibatomi, respectively. Many of these spiro ligands have shown either unique reactivity or more efficient or comparable to the hitherto known chiral ligands.

\section{Acknowledgement}

Prof Hiroaki Sasai is acknowledged for providing me an opportunity to work on chiral spiro ligands under The Japan Society for the Promotion of Science (JSPS) postdoctoral research fellowship at The Institute of Scientific and Industrial Research (ISIR), Osaka University. Special thanks to Dr Yugesh Kharel, Department of Pharmacology, University of Virginia, USA for literature collection.

\section{References}

1. (a) Comprehensive Asymmetric Synthesis I-III (eds. E. N. Jacobsen, A. Pfaltz and H. Yamamoto), Springer, Berlin, 1999. (b) Catalytic Asymmetric Synthesis (ed. I. Ojima), $2^{\text {nd }}$ edition, WileyVCH, New York, 2000. (c) G.-Q. Lin, Y.-M. Li and A. S. C. Chan, Principles and applications of asymmetric synthesis, Wiley \& Sons, New York, 2001.

2. (a) A. Miyashita, A. Yasuda, H. Takaya, K. Toriumi, T. Ito, T. Souchi and R. Noyori, J. Am. Chem. Soc., 1980, 102, 7933. (b) R. Noyori, Angew. Chem. Int. Ed., 2002, 41, 2008.

3. For reviews: (a) R. Noyori and H. Takaya, Acc. Chem. Res., 1990, 23, 345. (b) W. Tang and X. Zhang, Chem. Rev., 2003, 103, 3029. (c) A. Pfaltz, Acc. Chem. Res., 1993, 26, 339. (d) A. K. Ghosh, P. Mathivanan and J. Cappiello, Tetrahedron: Asymmetry, 1998, 9, 1. (e) J. S. Johnson and D. A. Evans, Acc. Chem. Res., 2000, 33, 325. (f) H. A. McManus and P. J. Guiry, Chem. Rev., 2004, 104, 4151. (g) G. Desimoni, G. Faita and K. A. Jørgensen, Chem. Rev., 2006, 106, 3561. (h) Y. L. Bennani and S. Hanessian, Chem. Rev., 1997, 97, 3161.

4. A. P. Krapcho, Synthesis, 1974, 383.

5. A. von Baeyer, Ber. Dtsch. Chem. Ges., 1900, 33, 3771.

6. For reviews on applications of chiral spiro ligands, see: (a) G. B. Bajracharya, M. A. Arai, P. S. Koranne, T. Suzuki, S. Takizawa and H. Sasai, Bull. Chem. Soc. Jpn., 2009, 82, 285. (b) J.-H. Xie and Q.-L. Zhou, Acc. Chem. Res., 2008, 41, 581. (c) K. Ding, Z. Han and Z. Wang, Chem. Asian J., 2009, 4, 32. (d) Z.-H. Zhang, Chinese J. Org. Chem., 2005, 25, 355. 


\section{Review}

7. (a) D. J. Cram and H. Steinberg, J. Am. Chem. Soc., 1954, 76, 2753. (b) E. Hardegger, E. Maeder, H. M. Semarne and D. J. Cram, J. Am. Chem. Soc., 1959, 81, 2729. (c) H. Gerlach, Helv. Chim. Acta, 1968, 51, 1587. (d) H. Gerlach and W. Muller, Helv. Chim. Acta, 1972, 55, 2279. (e) N. Harada, N. Ochiai, K. Takada and H. Uda, J. Chem. Soc., Chem. Commun., 1977, 495. (f) N. Harada, T. Ai and H. Uda, J. Chem. Soc., Chem. Commun., 1982, 232.

8. (a) J. A. Nieman, M. Paravez and B. A. Keay, Tetrahedron: Asymmetry, 1993, 4, 1973. For determination of absolute configuration, see: (b) J. A. Nieman, B. A. Keay, M. Kubicki, D. Yang, A. Rauk, D. Tsankov and H. Wiesser, J. Org. Chem., 1995, 60, 1918.

9. (a) A. S. C. Chan, C.-C. Lin, J. Sun, W. Hu, Z. Li, W. Pan, A. Mi, Y. Jiang, T.-M. Huang, T.-K. Yang, J.-H. Chen, Y. Wang and G.-H. Lee, Tetrahedron: Asymmetry, 1995, 6, 2953. (b) C.-W. Lin, C.-C. Lin, Y.-M. Li and A. S. C. Chan, Tetrahedron Lett., 2000, 41, 4425.

10. (a) A. S. C. Chan, W. Hu, C.-C. Pai, C.-P. Lau, Y. Jiang, A. Mi, M. Yan, J. Sun, R. Lou and J. Deng, J. Am. Chem. Soc., 1997, 119, 9570. (b) X. Li, C.-H. Yeung, A. S. C. Chan, D.-S. Lee and T.-K. Yang, Tetrahedron: Asymmetry, 1999, 10, 3863.

11. W. Hu, M. Yan, C.-P. Lau, S. M. Yang, A. S. C. Chan, Y. Jiang and A. Mi, Tetrahedron Lett., 1999, 40, 973.

12. (a) Y. Jiang, S. Xue, Z. Li, J. Deng, A. Mi and A. S. C. Chan, Tetrahedron: Asymmetry, 1998, 9, 3185. (b) Y. Jiang, S. Xue, K. Yu, Z. Li, J. Deng, A. Mi and A. S. C. Chan, J. Organomet. Chem., 1999, 586, 159.

13. C. W. Lin, C.-C. Lin, L. F.-L. Lam, T. T.-L. Au-Yeung and A. S. C. Chan, Tetrahedron Lett., 2004, 45, 7379.

14. (a) S. M. Lait, M. Parvez and B. A. Keay, Tetrahedron: Asymmetry, 2004, 15, 155. (b) S. M. Lait, M. Parvez and B. A. Keay, Tetrahedron: Asymmetry, 2003, 14, 749.

15. (a) M. A. Arai, T. Arai and H. Sasai, Org. Lett., 1999, 1, 1795. (b) M. A. Arai, M. Kuraishi, T. Arai and H. Sasai, Chirality, 2003, 15, 101.

16. S. Takizawa, J. Yogo, T. Tsujihara, K. Onitsuka and H. Sasai, J. Organomet. Chem., 2007, 692, 495.

17. M. A. Arai, M. Kuraishi, T. Arai and H. Sasai, J. Am. Chem. Soc., 2001, 123, 2907.

18. (a) T. Shinohara, M. A. Arai, K. Wakita, T. Arai and H. Sasai, Tetrahedron Lett., 2003, 44, 711. (b) T. Tsujihara, T. Shinohara, K. Takenaka, S. Takizawa, K. Onitsuka, M. Hatanaka and H. Sasai, J. Org. Chem., 2009, 74, 9274.

19. C. Muthiah, M. A. Arai, T. Shinohara, T. Arai, S. Takizawa and H. Sasai, Tetrahedron Lett., 2003, 44, 5201.

20. G. B. Bajracharya, P. S. Koranne, R. N. Nadaf, R. K. M. Gabr, K. Takenaka, S. Takizawa and H. Sasai, Chem. Commun., 2010, 46, 9064.

21. G. B. Bajracharya, P. S. Koranne, T. Tsujihara, S. Takizawa, K. Onitsuka and H. Sasai, Synlett, $2009,310$.

22. T. Tsujihara, K. Takenaka, K. Onitsuka, M. Hatanaka and H. Sasai, J. Am. Chem. Soc., 2009, 131, 3452.

23. K. Wakita, Gan B. Bajracharya, M. A. Arai, S. Takizawa, T. Suzuki and H. Sasai, Tetrahedron: Asymmetry, 2007, 18, 372.

24. T. Kato, K. Marubayashi, S. Takizawa and H. Sasai, Tetrahedron: Asymmetry, 2004, 15, 3693.

25. S. Takizawa, Y. Honda, M. A. Arai, T. Kato and H. Sasai, Heterocycles, 2003, 60, 2551.

26. K. Wakita, M. A. Arai, T. Kato, T. Shinohara and H. Sasai, Heterocycles, 2004, 62, 831.

27. P. S. Koranne, T. Tsujihara, M. A. Arai, G. B. Bajracharya, T. Suzuki, K. Onitsuka and H. Sasai, Tetrahedron: Asymmetry, 2007, 18, 919.

28. J. A. Nieman and B. A. Keay, Tetrahedron: Asymmetry, 1995, 6, 1575.

29. (a) M. J. Burk and R. L. Harlow, Organometallics, 1990, 9, 2653. (b) M. J. Burk, J. Am. Chem. Soc., 1991, 113, 8519.

30. Z. Guo, X. Guan and Z. Chen, Tetrahedron: Asymmetry, 2006, 17, 468. 
31. V. B. Birman, A. L. Rheingold and K.-C. Lam, Tetrahedron: Asymmetry, 1999, 10, 125.

32. J.-H. Zhang, J. Liao, X. Cui, K.-B. Yu, J. Zhu, J.-G. Deng, S.-F. Zhu, L.-X. Wang, Q.-L. Zhou, L. W. Chung and T. Ye, Tetrahedron: Asymmetry, 2002, 13, 1363.

33. S.-F. Zhu, Y. Fu, J.-H. Xie, B. Liu, L. Xing and Q.-L. Zhou, Tetrahedron: Asymmetry, 2003, 14, 3219.

34. (a) Z. Li, X. Liang, F. Wu and B. Wan, Tetrahedron: Asymmetry, 2004, 15, 665. (b) Z. Li, X. Liang, B. Wan and F. Wu, Synthesis, 2004, 2805. Also see: (c) M. Venugopal, S. Elango, A. Parthiban and Eni, Tetrahedron: Asymmetry, 2004, 15, 3427.

35. (a) W.-J. Shi, L.-X. Wang, Y. Fu, S.-F. Zhu and Q.-L. Zhou, Tetrahedron: Asymmetry, 2003, 14, 3867. (b) W.-J. Shi, J.-H. Xie and Q.-L. Zhou, Tetrahedron: Asymmetry, 2005, 16, 705. (c) H.-F. Duan, J.-H. Xie, W.-J. Shi, Q. Zhang and Q.-L. Zhou, Org. Lett., 2006, 8, 1479.

36. (a) Y. Fu, J.-H. Xie, A.-G. Hu, H. Zhou, L.-X. Wang and Q.-L. Zhou, Chem. Commun., 2002, 480. (b) A.-G. Hu, Y. Fu, J.-H. Xie, H. Zhou, L.-X. Wang and Q.-L. Zhou, Angew. Chem, Int. $E d .$, 2002, 41, 2348. (c) H. Zhou, W.-H. Wang, Y. Fu, J.-H. Xie, W.-J. Shi, L.-X. Wang and Q.L. Zhou, J. Org. Chem., 2003, 68, 1582. (d) Y. Fu, X.-X. Guo, S.-F. Zhu, A.-G. Hu, J.-H. Xie and Q.-L. Zhou, J. Org. Chem., 2004, 69, 4648 and references therein.

37. X.-X. Guo, J.-H. Xie, G.-H. Hou, W.-J. Shi, L.-X. Wang and Q.-L. Zhou, Tetrahedron: Asymmetry, 2004, 15, 2231.

38. W.-J. Shi, Q. Zhang, J.-H. Xie, S.-F. Zhu, G.-H. Hou and Q.-L. Zhou, J. Am. Chem. Soc., 2006, 128, 2780.

39. B.-M. Fan, J.-H. Xie, S. Li, Y.-Q. Tu and Q.-L. Zhou, Adv. Synth. Catal., 2005, 347, 759.

40. W. Zhang, L.-X. Wang, W.-J. Shi and Q.-L. Zhou, J. Org. Chem., 2005, 70, 3734.

41. Y. Yang, S.-F. Zhu, H.-F. Duan, C.-Y. Zhou, L.-X. Wang and Q.-L. Zhou, J. Am. Chem. Soc., 2007, 129, 2248.

42. (a) Y. Fu, G.-H. Hou, J.-H. Xie, L. Xing, L.-X. Wang and Q.-L. Zhou, J. Org. Chem., 2004, 69, 8157. (b) G.-H. Hou, J.-H. Xie, L.-X. Wang and Q.-L. Zhou, J. Am. Chem. Soc., 2006, 128, 11774.

43. S.-F. Zhu, Y. Yang, L.-X. Wang, B. Liu and Q.-L. Zhou, Org. Lett., 2005, 7, 2333.

44. (a) J.-H. Xie, L.-X. Wang, Y. Fu, S.-F. Zhu, B.-M. Fan, H.-F. Duan and Q.-L. Zhou, J. Am. Chem. Soc., 2003, 125, 4404. (b) J.-H. Xie, H.-F. Duan, B.-M. Fan, X. Cheng, L.-X. Wang and Q.-L. Zhou, Adv. Synth. Catal., 2004, 346, 625.

45. S.-F. Zhu, J.-B. Xie, Y.-Z. Zhang, S. Li and Q.-L. Zhou, J. Am. Chem. Soc., 2006, 128, 12886.

46. S. Li, S.-F. Zhu, J.-H. Xie, S. Song, C.-M. Zhang and Q.-L. Zhou, J. Am. Chem. Soc., 2010, 132, 1172.

47. J.-B. Xie, J.-H. Xie, X.-Y. Liu, W.-L. Kong, S. Li and Q.-L. Zhou, J. Am. Chem. Soc., 2010, 132, 4538.

48. S.-F. Zhu, J.-B. Xie, Y.-Z. Zhang, S. Li and Q.-L. Zhou, J. Am. Chem. Soc., 2006, 128, 12886.

49. B. Liu, S.-F. Zhu, L.-X. Wang and Q.-L. Zhou, Tetrahedron: Asymmetry, 2006, 17, 634.

50. (a) B. Liu, S.-F. Zhu, W. Zhang, C. Chen and Q.-L. Zhou, J. Am. Chem. Soc., 2007, 129, 5834. (b) C. Chen, S.-F. Zhu, B. Liu, L.-X. Wang and Q.-L. Zhou, J. Am. Chem. Soc., 2007, 129, 12616. (c) S.-F. Zhu, C. Chen, Y. Cai and Q.-L. Zhou, Angew. Chem. Int. Ed., 2008, 47, 932.

51. (a) W. Shu and S. Ma, Chem. Commun., 2009, 6198. (b) W. Shu, Q. Yu and S. Ma. Adv. Synth. Catal., 2009, 351, 2807.

52. (a) S. Wu, W. Zhang, Z. Zhang and X. Zhang, Org. Lett., 2004, 6, 3565. (b) W. Zhang, C.-J. Wang, W. Gao and X. Zhang, Tetrehedron Lett., 2005, 46, 6087.

53. (a) X. Cheng, G.-H. Hou, J.-H. Xie and Q.-L. Zhou, Org. Lett., 2004, 6, 2381. (b) X. Cheng, Q. Zhang, J. H. Xie, L.-X. Wang and Q.-L. Zhou, Angew. Chem. Int. Ed., 2005, 44, 1118. (c) X. Cheng, J.-H. Xie, S. Li and Q.-L. Zhou, Adv. Synth. Catal., 2006, 348, 1271.

54. (a) K. Shibatomi, T. Muto, Y. Sumikawa, A. Narayama and S. Iwasa, Synlett, 2009, 241. (b) K. Shibatomi, A. Narayama, Y. Soga, T. Muto and S. Iwasa, Org. Lett., 2011, 13, 2944. 